\title{
Fa (Standards: Laws) and Meaning Changes in Chinese Philosophy
}

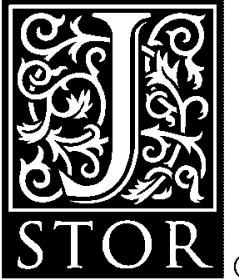

\section{Chad Hansen}

Philosophy East and West, Vol. 44, No. 3. (Jul., 1994), pp. 435-488.

Stable URL:

http://links.jstor.org/sici?sici=0031-8221\%28199407\%2944\%3A3\%3C435\%3AF\%28LAMC\%3E2.0.CO\%3B2-L

Philosophy East and West is currently published by University of Hawai'i Press.

Your use of the JSTOR archive indicates your acceptance of JSTOR's Terms and Conditions of Use, available at

http://www.jstor.org/about/terms.html. JSTOR's Terms and Conditions of Use provides, in part, that unless you have obtained prior permission, you may not download an entire issue of a journal or multiple copies of articles, and you may use content in the JSTOR archive only for your personal, non-commercial use.

Please contact the publisher regarding any further use of this work. Publisher contact information may be obtained at http://www.jstor.org/journals/uhp.html.

Each copy of any part of a JSTOR transmission must contain the same copyright notice that appears on the screen or printed page of such transmission.

JSTOR is an independent not-for-profit organization dedicated to and preserving a digital archive of scholarly journals. For more information regarding JSTOR, please contact support@jstor.org. 


\section{FA (STANDARDS: LAWS) AND MEANING CHANGES IN CHINESE PHILOSOPHY}

\section{Introduction}

The orthodoxy is that Chinese characters (1) have more meanings and (2) change meanings more frequently than words of other languages. One example is that of $f a^{\text {standards:laws }}$. The usual view is that the character means standard or to model for Early Confucians, Mohists, and Daoists, but for those called Legalists (and perhaps for Xunzi) it means laws. The paradigms of the legal use are Han Feizi and Shang Yang. Traditionally, Chinese accounts called them fa-jia ${ }^{\text {school of } f \text {, and we translate that as }}$ 'Legalist'. Typical meaning-change hypotheses tie such meaning changes to schools, times, and sometimes simply to particular thinkers or textual tokens.

Using the fatandards:laws $e x a m p l e$, I hope to reduce the allure of these familiar meaning-change claims in general. I believe they are endemic largely because the "translation paradigm" dominates Sinology. Simply put, we assume that in classes and with dictionaries and grammar books, we learn how to read (translate) Chinese. (We tend to learn Chinese grammar as a set of algorithms for translating correctly.) Then, armed with this prior, independent knowledge of meaning, we tackle the texts and come to discover what Chinese thinkers believed. The paradigm encourages us to think of translation as objective, disciplined, and basic. Interpretation - the theory of what philosophers believed-is by contrast speculative, subjective, and undisciplined. These attitudes coexist (surprisingly) with the platitude that the correct translation depends on Chinese characters having the same meaning as the translation term. It also survives our latent awareness that interpretation is equally about meaning and that meaning claims can be as controversial as belief claims.

A. Abstract. I will reject the translation paradigm and appeal to philosophical analyses of meaning and interpretation. In section II, I will reflect briefly on the issues that have driven recent developments in the philosophical understanding of meaning (II A), and show how interpretative theory links it to belief, truth, and reason. In II B, I will argue that implicit purposes of doing interpretative theory using these concepts together justify using meaning-change hypotheses only sparingly in interpretation. This will lead us to an account, in II C, of what we should require of someone who claims that such a meaning change has taken place. Finally, in II D, I will explain how the orthodoxy came to the view that Chinese meanings are particularly fluid.

Then I will look at the particular example of $f a^{\text {standards:laws }}$ I will argue in section III that advocates of the claim that fa changes meaning for the
Chad Hansen

Reader in the

Department of Philosophy at the University of Hong Kong

法

法家

Philosophy East \& West

Volume 44, Number 3

July 1994

435-488

(C) 1994

by University of

Hawaii Press 
so-called Legalists have not met their argumentative burden. The crucial element of that burden is elaborating and testing the "null hypothesis" - that produced by a meaning-constancy assumption. In section IV, I will spell out the implications of the claim that fa means law, and in section $\mathrm{V}$ explain in detail the original philosophical role of $\mathrm{fa}^{\text {standards }}$. Then in VI and VII, I will look at the background and detail of Han Feizi's theories. There I will argue that a consistent-meaning approach explains Han Feizi's crucial doctrines better than a meaning-change analysis does.

\section{Against Meaning-Change Hypotheses}

Consider the specific challenge to prove the case that the meaning of fa changes. We cannot point to a character's meaning-only to the character itself. We cannot point to a term's reference-only to the term and its context. Briefly, we see the character in spatial relations to other characters in the text. (In a living language, we could more easily appeal to the physical context.) We have a textual theory that sets this text among other texts. The textual theory gives each a nearly contemporaneous (and sometimes sequential) dating. How do we get from this data to claims about meaning and belief?

Normally we explain some texts as a whole by saying that they express a theory of law. In that interpretative claim, we are using a local concept-law. We treat the character as the central one in their expression of a theory roughly like one of ours. The standard version of the orthodoxy thus asserts that Legalists are Legalists because they advocated a political strategy based on something resembling a positivist legal theory. ${ }^{1}$ It assumes a conflict between law and morality. It analyzes laws as the ruler's promulgated, general commands, which count as duties only because he threatens retributive punishment.

Now the question will be: how much of the evidence for the claim that they advocate the doctrine depends on the orthodox theory of the meaning of the character $\mathrm{a}^{\text {standards:laws? }}$ ?hat is the evidence that Han Feizi is a legal positivist? He talks a lot about $f^{\text {standards:laws }}$ - for example, 禮 he contrasts $f a^{\text {standards:laws }}$ and $/ i^{\text {ritual }}$, and prefers $f a^{\text {standards:laws }}$. But we notice that Mohists and Daoists also talk about $\mathrm{a}^{\text {standards:laws }}$ and oppose $/ i^{\text {ritual }}$.

If at this point the orthodoxy asserts that they use $f a$ in the sense of standards, the circularity sets in. How do we know that Han Feizi uses it in a different sense-in the sense of law? Because he is a legal positivist? If the main evidence that he is a legal positivist is his use of fa in the legal sense, and the main evidence that he used $f a$ in the legal sense is his being a legal positivist, the circularity is complete. Use of this character signals the new doctrine only if we accept the orthodoxy's meaningchange hypothesis.

The translation paradigm short-circuits our natural suspicion by di- 
order, nature, and value of the two separate activities further disguises the circularity. If we treat translation as prior, objective, disciplined, and strict, then we can treat the presence of the doctrine of legal positivism as a genuine discovery. Only those who have learned how to translate can appreciate the discovery. Those who reject the discovery fail to understand that Chinese characters have many meanings, and that here the author used this character in the sense of 'laws'. All "competent" translators know this and know to translate it here as 'law.'

Suspicion arises when we notice that translators must simultaneously allege both the meaning change and associated belief. They support the attribution of belief, however, by then treating the changed translation as the "plain meaning" of the text. Sticking to "strict" translation signals decent respect for the "authenticity of the text." Thus, the translation paradigm treats translation as coming before interpretation. It paints interpretation (the attribution of belief) as speculative and undisciplined while treating translation as objective, disciplined, and comparatively straightforward. To challenge translation conventions is dangerous. It substitutes subjective, speculative, interpretative reactions for the plain fact of what the text says.

A. The Nature of Meaning. The hint of circularity in this translation model has been familiar territory for students of philosophy of language since Quine. He based his analysis of the underdetermination of translation on this interaction of meaning and belief. We must attribute meanings and beliefs together. We can defend multiple attributions of meaning if we suitably adjust the beliefs we attribute and vice versa. Given, then, that both meaning and belief are nonempirical features of texts, how should we go about deciding which pairing is correct?

Davidson developed the deconstructive hint in Quine that reverses the translation paradigm's familiar order. The test of any paired assignment must start with the beliefs, not the meanings. The meaning theory that generates the beliefs that pass the test is the correct theory of meaning.

Davidson's point reminds us of another feature Quine introduced into our understanding of meaning - semantic holism. Our attributions of belief (therefore, also, of meaning) depend on how we assign meaning to all the other characters in the texts. We look for a system of meaning assignments that, given the order in the texts, produce belief assignments that passed some test.

Perhaps part of the motivation for focusing on belief assignments is this: unlike meaning assignments, we have a test ready at hand for beliefs - truth. The kinds of tests we might propose for grading meaning assignments directly and piecemeal (for example, similarity to our own, familiarity, elementariness, or primitiveness) all seem intellectually dubious.

Chad Hansen 
Furthermore, choosing the meaning-belief assignment that enhances the truth of these beliefs captures our implicit, intuitive practice. Seeing the writings as true has notoriously been one way of "making sense" of them. An important theoretical advantage of the "principle of charity" buttressed the case for it. We could more easily think of interpretative theory as an explanatory theory. Something caused the beliefs we find in the texts. True states of affairs cause us to have the beliefs we have.

However, the principle of charity also presented equally well known problems. Critics had challenged the implicit confusion of understanding and agreeing with. A truth-based standard favors interpretations that made ancient, exotic thinkers agree with us, now. We are naturally suspicious of the popular interpretations of classical Daoism that "make sense" of it by making it assert quantum mechanics and special relativity theory. Beyond showing that the beliefs our assignment yields are true, we need to show that they are truths that are plausibly accessible to the writers of these texts.

So, thinking of interpretation in explanatory terms undermined the principle of charity. It is not simple truth that causes human belief. A cluster of psychological mechanisms explains belief in humans. These mechanisms include sense organs, inheritance of belief, inference from other beliefs, argument and agreement, and social pressures. Philosophical "truths" particularly worry us. They are deliberately remote from mundane truths about medium-sized animals and plants, accessible to anyone with normal human sense organs. Ethical truths raise related problems, and, as Quine had shown, even the allegedly mundane truths turn out to be problematic. Mere sensation cannot tell us to choose a meaning-belief assignment that says there is a rabbit out there rather than a piece of rabbit-stuff, an instance of rabbit-hood, a sequence of rabbit stages, or a collection of rabbit parts.

These reflections led many to alter the test and to embrace what Grandy (1973) called the principle of humanity. Here the standard for ranking meaning-belief assignments is not the truth of the resulting beliefs, but their psychological explainability. How good an explanation does the assignment offer for the writers' having arrived at the beliefs our assignment ends up attributing to them? One obviously important property of the body of beliefs given the principle of humanity is rational coherence. A natural way humans arrive at beliefs is by harmonizing and developing them from other beliefs they hold. Roughly, then, the principle of humanity says to promote coherence rather than truth (for the interpreter).

Focusing on these central interpretative concepts underlined the conceptual interaction of meaning, belief, truth, and reason. It has also Philosophy East \& West generated skepticism about the entire cluster. Skeptical treatments of 
meaning had already begun with Quine; Stitch and Churchland have doubted the scientific respectability of belief. Truth has been under attack since Wittgenstein (some would say Dewey), and reason has joined the ranks of suspicious concepts we allegedly spread on the world rather than read off it (Stitch, Gibbard). I have doubted in print that any similar cluster of concepts functions in pre-Buddhist Chinese thought. ${ }^{2}$

In the context of such doubts, I do not propose to treat meanings as determinate entities that resist change. Besides presupposing that meanings are real, that also would require settling the puzzle of what they are. Instead, I shall argue for a normative conclusion. In doing interpretative theory, we should be sparing in proposing such meaning changes. This normative conclusion derives from an analysis of the purpose of interpretative theory. Meaning and belief play complementary roles in achieving that purpose. So, in what follows, I shall remain neutral on whether meaning and belief are scientifically viable natural kinds and on which meaning theory is correct.

Still, I shall continue to use the cluster of terms. For all our doubts, we do not yet have a settled, scientifically respectable alternative to meaning-belief theory. In any case, we are assessing a claim put forward in the traditional terms - that the Chinese character fa changes meaning. We can only address the substance of that claim by attending to the existing norms for the use of our existing terms - even if we suspect we shall someday abandon them.

We can still use the spirit of the principle of humanity and its implicit technique of exploiting a rough analogy to ourselves. That does not mean we have to treat those we translate as having beliefs, far less as having the concepts 'meaning' and 'belief'. We simply suppose them to be in states roughly like those we are in when we routinely attribute beliefs to ourselves. Similarly, we shall not rely on any detailed account or theory of reason or coherence. We shall simply attend to what would make sense for someone who starts with a set of beliefs to add to that set.

On the same rough analogy to ourselves, we can ask under what conditions they might come to adopt new beliefs, to doubt things they earlier believed, and so forth. Possibly, the standards of what would "make sense" might change. As our theory develops, what makes sense may change in complicated ways. We could not now predict those ways simply on analogy to ourselves. We only assume that we could eventually understand and make sense of the connections among beliefs. We assume only that humans share the ability to learn the languages of other humans.

In arguing that we should use meaning-change claims sparingly in our interpretative theories, I am claiming that those who propose such theories owe us further explanation. I will also try to spell out the general

Chad Hansen 
content of the explanation, drawing on the implicit purposes we exhibit in using the interpretative language of meaning and belief. We should rely on meaning-change hypotheses sparingly because they undermine our purposes in doing interpretations. We can explore these purposes by looking at various theories of meaning without endorsing any particular one. We simply attend to what I will call the "good making characteristics" of various theories. Those features we cite and accept as favoring one theory against its rivals reflect the explanatory purpose of a meaning-belief theory. We can thus identify the purpose without deciding which theory is the best.

B. The Purpose of Meaning-Belief Theory. So far, of course, I have not explained why the meaning-belief link should favor meaning stability. Nor have I said why the translation paradigm inclines to the meaningchange claim. A traditional dictionary could in principle have contained only one English word for each Chinese term. We could combine a Quine view that interpretation attributes meaning and belief together with a thoroughly wanton ascription of meanings to terms.

All we have noted so far is that to attribute a meaning to a term is simultaneously to attribute beliefs to its members. We can adjust any meaning assignment to the facts of usage by changing our account of what the speakers believe and vice versa. Thus, Quine argues, no fact of usage can prove that one meaning-belief complex is more "correct" than another. If you adopt any one of them and assume the corresponding beliefs you can communicate fully with native speakers.

Quine, for example, could say that the expression "gor dhi ngraw xoo jrukshynn" (those oxen are ugly) means "the grass is green" (since oxen are usually around grass). Then, when someone at dimsum says, "cearng srik ngraw paakjrip" (have some beef tripe), he could choose between saying two things: (1) the term in that context now means beef, or (2) the speakers had an elaborate belief about how eating beef tripe is indirectly eating grass. There are simply too many ways of matching statements to truths if we allow meaning-change hypotheses. This is the kind of consideration that led Quine to conclude that no fact settles meaning claims. No meaning facts underlie our attributions of meaning.

Davidson's corrective emphasizes that the theory attributing meaning should do so systematically. It should assign meaning to expressions in ways that reflect their grammatical structure. This favors interpretations that do not freely alter meaning in every different use or context. We strive to find a meaning that fits the system of the language and explains all the uses and references of a term.

We have already noticed that Davidson's approach gives us a basis for rating some assignments as better than others. We also can motivate it on causal-explanatory grounds - as we did the principle of humanity. 
A language that worked in the way we envisioned above would be humanly unlearnable. We can explain how humans learn the meaning of their sentences only if the semantic rules trace the syntactic ones. Then the speakers of the language could construct, predict, and understand grammatical combinations they had not met with before. A language that did not have that feature would not be rational in my loose sense. It would not make sense to beings with our particularly human combination of mental abilities and limits.

The point is not that we can neatly separate meaning and belief. The point, rather, is that we attribute both to a population as a combined strategy to explain all their communication in context. The explanation will be better if we can give a constant theory of meaning to explain different uses. It will not merely be more elegant, simpler, and more plausible. It will have more explanatory power. When we strive for meaning stability, we achieve that implicit purpose of doing interpretative theory better. We attribute a complex of meaning and belief to the speakers in ways that explain the links between the uses of the term in different grammatical, physical, and conversational contexts.

Still another theory favoring stable meanings comes from the Strawsonian tradition. If we distinguish between a word and the use of a word (a word type and a word token), then we might explain meaning and reference/use as follows. We say that a word type has a meaning. In virtue of the word type's meaning, the word token refers to contextually appropriate objects and thus contributes to the statement token's truth. Thus, we shall think of tokens of a word as referring to specific objects, but not, qua token, as having a meaning. The word type, by contrast, will, qua type, have no reference but have a meaning-its potential to refer to this or that in context. To refer, we must use the word in some contextual statement.

Thus, we prefer not to say that the meaning changes with each different use in which reference changes. The salient examples here are indexicals. The word " $I$ " refers to a different individual when used by different individuals. That is a property of the word type. We should want to say that the meaning is the same for all English speakers and uses. That shared meaning of the word type explains why specific word tokens, utterances by different people in different situations, refer to this or that.

The causal or historical theory of meaning has dominated recent philosophical discussion. It gives a slightly different account of the relation of meaning and belief. This, therefore, is another good place to look for the implicit purposes of doing interpretative theory. Its chief feature is that in place of identifying a meaning with a descriptive phrase (a definition in, say, English or an ideographic description in Mentalese), causal-historical theory focuses on the coiner. Someone first used the word to refer to some object. She intended the word to apply rigidly to

Chad Hansen 
that type of object. Those who learn the term from that original coiner typically both intend and strive to refer to the same type. This ties meaning, the causal theorist argues, to that actual type, not to what the speakers believe about it.

Causal theorists urge this analysis especially for "natural kind" terms - grizzly bear, oak, hydrogen, and atom. Causal analysis has one advantage over any descriptions analysis: we can make sense of intellectual progress. Once we believed that dolphins were fish. We now know they are mammals. On causal analysis, neither the term 'fish' nor the term 'mammal' has changed meaning. The change was in our substantive scientific beliefs, not in semantics. The term "rigidly designates" the type even when our beliefs about that type change in basic ways.

The advantage that causal theorists appeal to is that this approach makes intellectual progress intelligible. We can make sense of discovering that we were wrong in our past beliefs. We once thought a sunrise happened when the sun moved through the sky. Now we think it happens because the earth revolves. We once thought the earth was a flat expanse of land surrounded by water; we now think of it as round. The meanings of 'earth', 'sun', and 'sky' have not changed, but our beliefs about them have. 'Sunrise' still refers to the same event-type, but it does not describe that event as we now understand it.

Rival "descriptivist" theories implicitly treat any key change in our view of a type as a change in meaning. Descriptivist theories, consequently, make intellectual progress problematic. As some Kuhnians have argued, if a word's meaning is a theoretical description, then we cannot unproblematically claim that Einstein's physics is an advance on Newtonian physics. They simply "define" 'mass' differently so that there is no neutral statement of any question that Newtonian physics answered wrong and Einstein's physics got right. The theorists of different times are simply speaking different languages. They do not really disagree. The appearance that the two theories conflict is illusory. So, too, is the appearance that our knowledge has increased. We have simply changed languages and the two beliefs are incommensurable.

The positivist tradition was one target of causal theorists. It, too, had tried to deal with the stability of meaning and avoid these problems with a descriptivist account. This used the theory of contextual definition. We can give the meaning of a term without giving an explicit formula or rule for its use. We simply give a rule for substituting other terms in different contexts and thus show how to "eliminate" the term. Giving the substitutions together with the rules that trigger them in contexts is giving our theory of the meaning of the term. This implicitly treats the meaning as more general and more stable than the particular uses.

The causal theory also purports to correct endemic mistakes in more Philosophy East \& West traditional Western semantic theories. Western folk theory of meaning 
treats meaning as an intrinsically representational mental item-the Mentalese description. This, notoriously, makes all communication paradoxical. Each of us arguably has a different mental construct for each English word. Meaning, on this traditional analysis becomes private and subjective and the appearance of communication an illusion. The conventional analysis joins the causal analysis in both these conclusions. If meaning is a convention, then it is public. Individuals may get the convention wrong, but they do not change it by misunderstanding. Conventions also have a certain stability through time-though perhaps not as "rigid" as that envisioned by the causal theory.

The descriptive theory or the commonsense ways of speaking that blur meaning and belief also block any chance of successful communication between parties who disagree. In ordinary speech, we say "For Mencius 'morality' means something internal, and for Xunzi it means something external." This uses the word 'means' to talk about their different theories. That claim says the same thing as "Mencius believes morality is internal and Xunzi believes it is external." It seems a positive feature of theories like the causal and conventional meaning theory that they keep meaning and belief claims more distinct than this. People can use the meaning conventions to state different and even conflicting beliefs.

The point remains even when the beliefs in question are beliefs about the meaning (definition) of the term in question. The causal theory reminds us to treat even different philosophers' deliberate definitions as merely rival theories of the same subject matter. The subject matter is the term's meaning. On the causal analysis, that meaning is the object's essence. On the conventionalists' analysis, it is the unformulated but public conventions governing use of the word.

Disputing rivals use the same word in conducting their debate, and they assume it has a common meaning for them both. They disagree either about the analysis of that term or about the essence of the type to which it refers. Each assumes that one of them is wrong about some objective matter. (Each usually assumes that, in particular, his rival is wrong.) A philosopher's definition does not settle this issue. It merely gives his view on it. Such pronouncements do not fix the meaning of our terms.

Our linguistic competence is our mastery of our linguistic community's conventions. Those conventions settle what his words refer to, not my pronouncements about the word. If he says, "by 'nature,' I mean whatever occurs during life," he may be right or wrong. Even if he announces it as a firm resolve to use the word that way, he may or may not successfully conform to that resolution. Even if he does, it could not change what any of his pronouncements strictly means. It effectively conveys his intention to say something else and thus helps us understand his point. His new theory may eventually become common belief

Chad Hansen 
and thus part of the inference potential of the term. We will consider this result below when we talk about how meanings do change.

The important point here is about our implicit purposes in advancing meaning-belief theories. We seek to understand the language-based interactions in a linguistic community. We notice that members of a community sometimes debate. They disagree-have different beliefs. We more naturally explain that interaction by saying that they use the same word with the same meaning and disagree in their beliefs. We also say their beliefs change over time. A sufficiently stubborn "radical" Quinian, however, could instead offer a translation manual in which $A$ and $B$ simply speak distinct subdialects. The appearance of a debate, she would say, is illusory. They are simply not communicating.

Recall that a similar problem plagued the early versions of ethical Emotivism. Naturalists criticized it for making the appearance of substantive moral debate a mistake. Emotivists themselves took Emotivism to entail that disputants misled themselves when they thought they were having a substantive moral discussion. They falsely assumed that one of them was right and one wrong. They assumed there was a separate moral fact that makes one right and the other wrong.

Naturalists had an easy counterattack. Your analysis of the meaning of moral terms cannot be correct if it so drastically alters our conception of what we are doing in moral debate. It suggests that no one in the community of moral advocates understands the moral terms. If they did, they would stop debating. We normally assume that the bulk of native speakers do understand such simple terms. Therefore, it clearly is part of the meaning (inference potential) of 'moral' that getting the right answer is a reasonable aim of discussion. The conventions of the group underlying the use of these terms include that they take reasonable debate of the ethical matters seriously.

We object to using meaning change liberally in interpreting Chinese philosophy on similar grounds. If meaning changes whenever theory changes, then the two schools or writers are simply not communicating. Technically, they are not using the same language. Once they understand that they are speaking different languages, they will see that they have no real disagreement and cease to waste time in discussion.

Their belief that they are really disagreeing is an illusion-declares the interpreter. The problem is not merely the interpreter's implicit arrogance in assuming he understands the language better than the participants. His stance prevents us, now, from being able to make sense of the debate. That is because his position amounts to the claim that the debate really makes no sense. He abandons one of the purposes for which we make a meaning-belief distinction in interpretative theory.

Of course, sometimes there are such breakdowns in communicaPhilosophy East \& West tion. The point is that they are breakdowns, not the normal case. In the 
normal case, we hold meaning constant and allow for differences in belief. This is the more systematic, elegant, natural way to explain the community's speaking and writing. We should, thus, construe meaning broadly, abstractly, and generally enough to underwrite most of the existing views in the community. We should not treat all disagreement as differences in meaning, thus making rival factions speak different languages. The meaning makes possible (and possibly productive) the activity of debate, of discussion, and of disagreement. It maintains the community as the beliefs change.

Both parties in the debate assume that the reasons they give for their beliefs are good reasons-better reasons than those given by their rivals. Still, we can safely assume that they can recognize and respond to the rival reasons. The rivals produce reasons we can recognize as germane and deserving response. We engage in the debate because we think that we can each recognize and weigh the force of the reasons for rival beliefs. Thus, one productive way to analyze "knowing the meaning" is to be "able to appreciate what the community recognizes as reasons for different beliefs." The terms of debate pick out the subject matter and underwrite all the reasons a community might give and recognize as pertinent considerations for rival beliefs and for expanding beliefs.

My strategy in this essay is related. Rather than try to decide which meaning theory is correct or what the nature of meaning is, I focus on what we recognize as reasons in favor of each. Then I use those considerations to locate our implicit purpose in attributing meaning and belief. We take our recognition of reasons favoring a theory as a good guide to our intuitive understanding of the point of making a meaning-belief distinction. We respond to the implicit purposes that launched meaning theory in Western philosophy. We want to explain the system and detail about a community's use of a term. ${ }^{3}$

All the theories make meaning more stable-something we can use to explain other changes in the functioning of language. The other changes explained include changes in reference, belief, or traditional translation. Here both the causal and conventional theory point to their superior ability to explain communication through time, across speakers or schools, and through normal advances in theory. These theories contrast with a commonly recognized failing of traditional meaning theory. That theory, enshrined in some familiar ways of speaking, makes meaning so subjective it makes communication and mutual understanding enigmatic.

In sum, reflecting on the purpose of attributing meaning, we see that we cannot achieve that purpose when we wildly attribute change in meaning. To resort to meaning change claims is to give up the goal of explaining normal, successful conversation and interaction. This does not mean we can never do it. We would entertain such changes when we

Chad Hansen 
have good reason to conclude that normal communication has broken down, for example when we can find no way to make sense of the exchange or intellectual development. We cannot justify the claim that meaning has changed simply by citing a change in reference, a difference in use, a dispute within the community, or an advance in knowledge. We achieve our normal explanatory purpose better when we represent these normal occurrences against a background of linguistic continuity. Meaning change is a departure from that norm, and when we postulate one, we owe a substantive showing that claiming such a departure is justified -the burden of proof is on the meaning-change theorist.

C. Mechanisms of Meaning Change. Again, we have not argued that meaning cannot change. In fact, each of the theories entails that meaning does change in certain situations and in certain ways. Obviously, the causal theory presents language as having much more constant meaning than does Traditional Western theory. It does, however, recognize meaning change. Normally, we succeed in referring as our teachers do. When we fail, our teachers or other speakers normally correct us. The typical explanation of a breakdown for the causal theory is an embedded mistake. These mistakes are common; people do misuse words. However, the usual pattern is that others in the linguistic community notice, criticize, and correct the mistake. It does not change meaning unless it somehow survives this normal process and gets embedded in a tradition. ${ }^{4}$ The same causal mechanism that explains meaning can, thus, explain meaning change. Opinion leaders' mistakes embed themselves. The community so respects or fears the person who first makes the mistake (he may be the leader of a school, or someone politically ruthless) that they emulate rather than correct him.

Conventions also change. They may change in a similar way-as conventional perpetuation of a mistake in some earlier convention. They normally, however, occur gradually as accumulations of original or elaborating extensions of existing conventions. These changes will be almost imperceptible to the participants. Even external observers will only notice them after considerable accumulation.

The intimate interrelation of meaning and belief also carries implications for meaning change. I noted above the leeway we normally grant individuals to depart from conventions in metaphor as well as provisionally to employ controversial stipulative definitions. Granting such leeway figures in another way that meaning actually does change. The metaphorical expression can be so engaging that it becomes common-a cliché. The metaphor ossifies into conventional use-the process that led Nietzsche to describe truth as "dead metaphor." Metaphors get absorbed into the conventional ways of speaking. They become part of the meaning. 
Similarly, once-disputed theories that are presented using arguments that depend on controversial stipulative definitions can become widely accepted. The conventional inference potential of the term then grows. Here we see, in more explicit form, the relation between meaning and reasons for belief. One who understands the meaning can follow the argument for a position. When the position becomes "conventional wisdom," the inference potential of the term reflects that change. This is why it is so easy to slide into the view that to understand the meaning is to accept the truth of the natives' beliefs. That would, of course, violate our desideratum. Rival theories may both reach their conclusions from different stipulative definitions. They can understand and follow each other and an audience can follow them both.

We will be torn about dividing the explanation between meaning and belief when theory changes radically enough. When a theory postulates new theoretical objects, we may begin to use an old word ambiguously for the old and new objects. Theorists may comment on their intended difference and give instructions or pronouncements that signal their intention. They draw attention to and distinguish their theoretical roles. A stipulative definition helps restrict the word to its new theoretical role. If the new theory is successful, the word's new role may eventually become its primary role as the old theory disappears. Alternately, as we become more aware of the difference, we may start to reserve one term for the new role and use what was once a synonym for the original role.

These are plausible outlines. They illustrate the story we must tell along with any argument that meaning has changed. This type of meaning change will normally occur mainly where (a) the theory relates the roles inferentially, (b) no word existed for the newly intended theoretical role, and (c) the coiners were ignored or they elided the difference in sense or lacked the originality to coin a new word. Theorists may, alternately, note the different senses and keep the accepted ways of speaking.

Most clearly, meaning change can come about when we import foreign ideologies and translators use existing ideographs to limn key terms in the foreign theories. These characters then start to exhibit the inferential connections of the alien conceptual scheme. When the imported theory is far different, the term may come to refer to a different type-to the type intended by the coiner of the foreign term. It is in such cases that the meaning-change hypothesis is most plausible. ${ }^{5}$

The onus, then, that lies on the advocate of meaning-change hypotheses is (a) to show that we cannot satisfactorily explain those differences in use, reference, or belief as differences tied together by a common meaning of a shared language and (b) to specify and explain the mechanism by which the meaning change took place. We treat meaning-change theories as explanations of failure. The interpreters ad-

Chad Hansen 
mit that they cannot explain or make sense of the apparent reasons the different factions gave for their positions. We pronounce the participants mistaken about the implications of their own language use, about the nature and character of their dispute. We allege that communication between them has broken down. It is not enough that neither argument clearly wins. The failure hypothesis would suggest that they were not even able to consider, weigh, or respond sensibly to the arguments given by the other side.

This can, of course, happen, but it is not the normal case. When we see clear evidence of such a breakdown in communication and a complete failure to connect in debate, we can start to look for some mechanism of meaning change to explain it. We would meet this onus when we show that postulating a breakdown explains the text better and can, itself, be explained. First the meaning change must yield a considerable explanatory advantage over treating meaning as constant. It must outweigh the normal theoretical, psychological, and conventional reasons for the null hypothesis.

The null hypothesis is the interpretative theory (account of meaning and beliefs) that assumes the normal communication conditions to hold. It treats meaning as shared among the writers of the same language who disagree about philosophical issues. It treats meaning as constant even as knowledge progresses and as theory evolves in the community. Arguing for a meaning change thus requires at least elaborating the null hypothesis for evaluative comparison. We must first see how the assumption that the term did not change meaning attributes and explains the different beliefs in the community through time. Only if we can show that it wholly fails to make sense of the texts can we justify the meaningchange theory.

We must, then, show that assuming that the term's meaning did change does attribute beliefs to the community that we can plausibly explain. This is an unexpectedly high hurdle. In asserting that the meaning has changed, we have abandoned the right to explain by appealing to normal communication and reasoning practices. Unless we rely on the details of some mechanism, we have no reason for saying that it changed to "this" rather than an infinite range of "thats." Foreign import, extraterrestrial visitations, descent from a common language, divine inspiration, innate ideas, and so on are among the available (sometimes shockingly common) explanations. ${ }^{6}$ Such breakdowns are normal. The problem is that we lack an account of the "normal" result of such a breakdown. After postulating such a breakdown, the meaning we attribute threatens to be ad hoc.

D. The Translation Paradigm and Meaning Change. It remains only to say Philosophy East \& West why the translation paradigm has found the theory that Chinese charac- 
ters change meaning frequently so tempting. We can trace part of the motivation from considerations we have explored above. First, the principle of charity, combined with a practical requirement to find an English word for the translation in this context, leads quite obviously to different English words being used. We thus come to associate each character with several different English words. We learn to select different members from the list for different contexts. We select the member that produces a sentence we find most nearly true or most comfortably familiar.

Further, it can easily strike us that Chinese philosophers deliberately avoid the stereotypical, Socratic move. They seldom ask, "What do you mean by X?" Definition simply does not play the central role in Chinese philosophical discussion that it did in the Western tradition. Interpreters, in reaction, become willing to treat almost anything a philosopher says using a term as a definition of that term. This perhaps stems from combining the conviction that Chinese philosophy is philosophy with a traditional conception of Western philosophy. When we add another traditional, folk philosophical belief, that meaning is in the private individual mind, we get the conventional conclusion. Each utterance using a term becomes what the philosopher successfully means by the term, and all his declarations become "true by definition in Chinese." We not only satisfy the principle of charity in making them true; we explain their truth as analytic. We need only understand that Chinese words change meanings especially freely.

We could, however, interpret both these practices in the spirit of contextual definition explained above. We could insist that the various translations and pronouncements are consistent with a single coherent concept. That presents us with a sometimes challenging task of tying the alternatives together with some coherent theory of the meaning. I suspect that another feature of our training mitigates against this, however. The metatheory of the relation of translation and interpretation avoids the conclusion that accepted translation practices enshrine a conventional interpretative theory. We still try to understand our learning classical Chinese on the analogy of learning a living language. (Note the endemic fascination among classical scholars with their various unpronounceable systems, each purporting to capture how ancient writers pronounced each character.) Scholars aspire to a state similar to that of being a near-native speaker of modern Chinese. Yet, when we learn classical Chinese today, we still learn it typically in the form of translation strategies. Most "grammarians" of classical Chinese still state their "grammar" in the form of translation algorithms. Ancient Chinese linguistics is marked by more interest in reconstructing ancient pronunciations than developing a principled, phrase-structure grammar.

We cannot, of course, tie classical Chinese to the world via the actual relations to the world that comes from living in a community of

Chad Hansen 
classical speakers. We cannot learn intuitively to govern our mutual, practical relations with their language. We cannot make them seem natural to us via their incorporation into our daily social lives. We can only "master" the language by treating the conventional translations (whether English, modern Chinese, or Japanese) as unquestioned second nature. Mastery comes, thus, to require unreflective, credulous acceptance of traditional views of both meaning and belief.

Thus, we confuse becoming fluent in a conventional interpretative theory--at being native speakers of a school of translation - with being a native speaker of a language. We blur the valid standard of correct language use (endorsement by other speakers) with a specious standard of theory choice (endorsement by other theorists). We implicitly treat schools of translators as ersatz linguistic communities. To speak a living language correctly is to have other native speakers accept our speech as normal and interact with us. To know ancient Chinese is to have other translators of classical Chinese agree with us. This failed analogy tempts us to suppress the sense that the conventional English translations are words. We treat the meanings of the separate English words as the separate meanings of the ideograms. I have called this the "English-is-theonly-real-language fallacy. ${ }^{\prime 7}$

Although this partly explains the Western willingness to accept doctrines of meaning change, it does not explain why they are there to be accepted in the first place. We do hear such claims from Chinese as well as Western scholars. (Of course, the same explanation works for Chinese scholars who say such things in English.) The blurring discussed above would also have characterized the first encounters of Western missionaries and Chinese scholars. Knowing Chinese would have seemed to require accepting the then orthodox interpretative theory of Chinese thought-accepting the interpretative views of their living Chinese teachers. Indeed, part of the explanation of the orthodoxy that Chinese meanings routinely change is an engaging interaction of distinctive features of Chinese and Western ways of talking about language.

Classical Chinese philosophy did not use concepts such as meaning or belief in their theory of language. I will not go into the details of their linguistic theory here. Briefly, in the classical Chinese view, all dispute is disagreement about the reference, scope, or use of crucial terms. To have a disagreement is to use language differently, for different objects, and to classify differently. The logic of the interaction of meaning and reference, as we saw above, shows that we should avoid translating this view as saying that meaning changes between disagreeing parties in a dispute.

This theory of use underlay traditional Chinese dictionary construction. Chinese dictionaries, thus, routinely consist of etymologies followed by long lists of alternative substitutions. Each gives an example of a char- 
acter's use drawn from literature with a substitute character for that context.

What produces the familiar view that Chinese characters have many meanings is interpreting this against the background of our Western dictionary theory. It centers on the philosophical concept of meaning and definition. Each entry seeks to give a distinct rule of use. We translate the Chinese dictionary practice into a Western dictionary idiom (infused with these philosophical notions of meaning, concepts, content, and ideas). We tend, thereby, to treat Chinese dictionary practice as showing that each character has five to fifty different "meanings."

When Western scholars found the Chinese theory of their own past tradition, Confucian scholars already had several hundred years' history of reconstructing and interpreting their tradition. Western translators, as we saw above, might confuse learning the current Neo-Confucian conclusions in that project with learning a living language. I will not add much detail here to the long debate about the objectivity and reliability of those Confucian interpretations. The logical point is that they are interpretations.

Ming or Qing dynasty scholars had an established interpretative tradition. We adopt an attitude formally like the one we adopt toward prior Western interpreters. We mix skepticism with respect for their scholarship in recognition of the fact that we inevitably draw on their prior work in our current theorizing. However, we do not want to confuse learning these important interpretative theories with learning a living language.

We can ask, still, why would the Neo-Confucian project have bequeathed these meaning-change conclusions to the interpretative tradition they taught Westerners? One possible answer draws again on our reflections above. Confucianism resembles both a religion and a political party; Confucians are a combination of priests, lawyers, and philosophers. They do not treat ideological and interpretative issues as detached intellectual exercises. They rightly or wrongly view Confucianism as the authentic Chinese philosophy, in contrast to Buddhism. For them, as for many early Western interpreters, Chinese thought is Confucian thought.

This commitment encourages them to view Confucianism as an independent and integral system of thought and practices derived from a semidivine founder-Confucius. Confucian interpretative motivations are, thus, the obverse of those we have been eliciting from Western interpretative practice. They postulate meaning changes for the same reasons that Western interpretative theory would avoid them. Postulating meaning changes insulates classical Confucianism from its classical rivals and from the threat that Confucian conclusions do not follow from pure "Chineseness."

Confucianism prefers the outcome that concludes that Daoists and Legalists misused the language, missed the point, and changed the sub-

Chad Hansen 
ject. They prefer the conclusion that only Confucius and Mencius understood the crucial terms of debate. Taking their native critics seriously threatens rather than promotes their purpose. Postulating breakdowns in communication justifies otherwise sincere and serious scholars in dismissing the criticisms of Confucianism made by contemporary Chinese philosophers. They were simply (and erroneously) talking about something else!

The meaning mechanism we have discussed explains how these Confucian views came to dominate early Western studies despite longstanding natural skepticism about Confucian objectivity. We learn the meaning and belief together! When we try to satisfy our teachers that we understand the language, we accept their existing beliefs and rationales for their interpretation. Asserting that Daoists believe in the mystical, metaphysical Dao entails asserting that their use of Dao means "The indescribable, Absolute, indivisible creator of heaven and earth and all things" and vice versa. The theories that Han Feizi is a legal positivist and that $a^{\text {standards }}$ means laws in his writings do not rest on some neutral, independent ground. They support each other.

No conscious, deliberate distortion explains this result. Habit and learned beliefs drive this translation practice more than conscious reflective design. Still, the unnoticed interplay of meaning and belief assumptions gives us good reason to set aside the otherwise reasonable, conservative principle of accepting existing theory. It is rational on the assumption that a reliable process produces the community consensus. When the sole valid reason given for the consensus is that it is the consensus, the principle loses its appeal in theoretical matters. Advocates of meaning-change hypotheses cannot appeal to existing translation practice to meet the burden of proof.

In the particular case of $f a^{\text {standards:laws }}$, I would argue that the meaning did change - a century later. The mechanism was the importation of a foreign idea system and the appropriation of $f a^{\text {standards }}$ as one common translation for 'dharma'. Neo-Confucians looked back at their own classical tradition through the lens of six hundred years of Buddhist intellectual domination. Westerners found the Indo-European concept to be close to their own familiar commonsense notion of law or principle. The modern discovery, associated especially with Creel, was that fa had also meant 'standards'. Psychologically and epistemologically, the 'law' translation lies deeper in our consciousness.

In summary, the reasons for distinguishing meaning, use, belief, and reference are that they play different, interrelated, roles in the structure of an explanatory, interpretative theory for a language. Together they help us explain meaningful disagreement within a linguistic community and the variety of reference and use. They enable us to explain meaningful intellectual progress over time. These explanatory purposes suggest a 
policy of postulating meaning change sparingly and only when we find evidence of the mechanisms of meaning change. We should not resort to meaning-change claims whenever we find differences in expression, reference, or belief. Doing so undermines the attempt to explain intellectual progress in the normal way.

These considerations apply even when the debate is about the meaning of the term itself. When philosophers appear to offer what we might identify as explicit definitions or theories of what their term means, we should take the contextual implication seriously. They and their philosophical rivals disagree about something. Neither disputant becomes right simply by announcing his theory. Both think they are giving an account of the objective, public character, not of their subjective, idiosyncratic reaction to it. Even when a writer announces an apparently sincere resolve to use a word according to some explicit formula, we need not assume that he succeeds. He will have the same difficulty that we all do in detaching ourselves from our lifelong training in the public conventions of language use.

Positively, we meet the burden by comparing the null hypothesis to the suggested meaning change. The change should result in a clear explanatory advantage in accounting for the resulting beliefs. It must be a significant enough explanatory advantage to outweigh the implicit implication of a breakdown in normal communication practice. The advocate should supplement that comparison result with some explanation of the mechanism of meaning change. She should show how the error was made and why it persisted in the face of the normal mechanisms of meaning preservation. Simple appeal to an alleged consensus of translators or tradition of interpretation cannot justify meaning-change hypotheses.

\section{A Survey of Arguments for the Falaw Meaning-change Hypothesis}

Have any arguments for the meaning-change hypothesis applied to fa met this burden? Deliberate, explicit argument, as I have complained, is rare. The norm is to state meaning claims as if they were empirical observations for those who "know" Chinese. Three recent writers span the range of current theories of the term $\mathrm{fa}^{\text {standards }}$. All accept the orthodoxy that $f a^{\prime} s$ meaning changes. One position emphasizes the law sense and expresses reservations about Creel's standards analysis, even for the early thinkers. The second approach emphasizes the standards analysis and the meaning change to law as a minor adjustment. The middle position takes the meaning change at full value. It treats the two meanings as independent and the change as a real, localizable, and significant meaning event.

Schwartz accepts Creel's view that 'laws' is "often highly misleading $^{\prime \prime}$ and offers to "consider its many semantic extensions." He actually

Chad Hansen 
gives an elaborate and insightful statement of the 'standards' meaning: "a prescriptive method or techne designed to describe the rules of a craft or political techniques designed to control social behavior." ${ }^{\prime 9}$ Still, he insists, "It still remains possible that in its original meaning, the word fa may have referred to penal law and it is often 'closely associated' with the more specific word hsing [xing], undoubtedly meaning 'punishment' or 'penal law." He follows this denial by turning his attention to

刑 $x$ ing ${ }^{\text {punishment }}$ rather than $\mathrm{fa}^{\text {standards }}$. Then the possibility metamorphoses into settled fact, which Schwartz combines with another possibility: "With the rise of Legalism, with its orientation toward the forcible imposition not only of penal law but of institutional models of all sorts, it is possible that the coercive connotation of the word $f a$ is very much reinforced." 10

Schwartz' presentation confuses the substantive task of showing that a meaning change actually took place with the conceptual task of showing that it was possible. Of course any symbol may bear any possible meaning; the question is whether the community's use actualized one particular semantic possibility. He allows that, for many texts, "a good case can be made" that law is a misleading translation. I have argued that what he must show is that for at least some texts the law translation clarifies or improves the account of the views in text. The improvement must outweigh the implicit cost of claiming a breakdown in communication.

We may understand Schwartz differently. He may not be arguing for the meaning change as much as maintaining that the onus lies with those who challenge the existing translation-interpretation practice. Thus, he good-naturedly teases Creel for his protective attitude toward Shen Buhai, whom tradition normally considers a Legalist. Still, when both Schwartz and Creel talk about Shang Yang and Han Feizi, they agree that the proper translation is 'law'. They agree on that, and they agree that the latter advocates a political view which is similar to classical Western legal positivism. Creel said that Shen Buhai was not a Legalist because he did not talk about fa in the sense of law.

As we saw, the argument for this "observation" is that Shen Buhai does not advocate a positive rule of law as much as a bureaucratic method. Schwartz retorts in the same spirit that "the system did not preclude capital punishment."11 This shows that both implicitly recognize that a character's sense in stating one belief depends on that belief's connection to other beliefs-specifically here about punishment and coercion. What we need from both is a clear statement of what connection between beliefs about punishment and fa warrants the conclusion that fa means law. If it does, then we attribute to Han Feizi the specific theory of law expressed in his statements about fa. We need constructive argument that the attributing of that theory of what we call 'law' to him 
illuminates or explains his views on government, coercion, and punishment better than the theory of standards would.

Graham lays the basis of my denial of the meaning-change hypothesis. He similarly gives a careful and detailed account of the early 'standards' meaning, stressing the connection of fa and measurement. He explains the novelty of the Legalist position as lying only in repudiating the view that the fa require cultured gentlemen to use them. ${ }^{12}$ He then provides this exiguous motivation for clinging to the meaning-change hypothesis: "It is standards enforced by punishment (what for us is penal law) which get fully codified." ${ }^{13}$ He then concludes, "The scope of fa thus contracts towards what in Western terms is law."

Graham's statement has this strength: it recognizes that the alleged meaning change requires that the range of conventional denotations must "contract." It must come to denote only a subset of its original range if the meaning change has occurred. Still, he does not acknowledge the obvious difficulty in showing that a range of denotation has shrunk. Plainly, a particular referential use, even if regular and consistent, cannot show that the denotation has shrunk. We can only show that by a denial of reference (or a "pattern" of avoiding use). Unless writers explicitly reject using the term to refer to part of the prior denotation, any reference will still be consistent with the null hypothesis. The meaning changes (contracts) only when it is conventionally unacceptable to use the word for anything other than a law.

Especially puzzling, therefore, is that Graham immediately takes the claim back. He continues in the same breath, "but even among those classed as Legalists it can include, for example, methods of regulating the bureaucracy." If it includes such things, then the scope does not consistently contract. We again lack any reason to say the meaning has changed. Graham's way of conforming to the translation tradition requires that the same speaker use the term with alternately a narrow and a wide reference. The natural conclusion, since this alleged Legalist used the term with the entire traditional broad scope, is that $f a^{\text {standards }}$ still has the same meaning.

The most promising start to a discussion of the meaning-change hypothesis among modern commentators is Roger Ames' The Art of Rulership. ${ }^{14}$ Ames announces an intention to do something that would help relieve the burden. He offers to "discuss the evolution of fa from its primary meaning of 'model or standard' to the notion of 'penal law.'" Between that statement and the exposition, however, Ames' focus shifts. His discussion neither proves that the meaning shift took place nor explains why it did.

What instead follows that optimistic beginning is Ames' using the translation orthodoxy in a different project - the study of the evolution of legal theory. He looks at changing beliefs rather than changing mean-

Chad Hansen 
ings. He surveys classical Chinese doctrines about penal law relying on the meaning-change hypothesis to identify these doctrines..$^{15}$ In the place of the promised proof or explanation, Ames states the traditional theory wrapped in a hydraulic metaphor. "Only well into the Warring States period when the Legalist theorists had taken over this character and injected it with their own meaning did it come to connote 'penal law'" (italics mine). This metaphorical "explanation" (one envisions Han Feizi holding a syringe in one hand and the struggling character in the other) is not among the mechanisms we have identified for meaning change. And, beyond this, Ames neither explains how he identifies these different connotations nor attempts to justify the claim that they have changed. ${ }^{16}$

So Ames, Graham, Schwartz, and Creel all take the meaning change as given, and read the texts on that assumption. None seriously entertains or experiments with denying it. No one tests the null hypothesis. Ames simply translates the character as 'standards' until he gets to Xunzi and conventionally recognized Legalists, and then he translates the term as 'laws'. As with Graham and Schwartz, any confidence in this translation comes either from confidence in the tradition of change coupled with question-begging confidence that Han Feizi is a legal positivist. That confidence derives from the translation practice.

IV. The Meaning of Law: Inferential Relations

Although these presentations are inadequate, they do illustrate several important points. The exchange between Schwartz and Creel reminds us that translation always involves two theories of meaning-one for the target language and one for the translating language. Can we say what kinds of connection to other concepts-punishment, coercion, rules, sentences, morality, rights, society-make some term a concept of law? Our task requires that we isolate some central ways the Western concept of law is related to similar concepts. Let us review briefly these key inferential connections. We can, then, compare them with the terms of Chinese argumentation surrounding $\mathrm{fa}$.

A. Law and Laws: Sentential Form and Penal Content. We often forget that the Western term 'law' is not exclusively juridical. It has a primarily linguistic use. Laws are universal propositions (sentences) with either descriptive or prescriptive necessity (causation or obligation). Scientific laws are universal and necessary descriptive sentences. We routinely subdivide prescriptive laws into moral, prudential, or penal laws.

The more familiar traditional Western debate about the concept of law concerns mainly the status of coercively enforced, codified, prescriptive laws used by governments. These we isolate as human or penal law. A common conception informs the long historical controversies that theorists understood as defining law. Natural-law and positive-law theorists presented rival theories of what penal law was. They operated 
with the same term and assumed that, at most, one of their theories correctly captured that common meaning. The points of agreement and the reasoning both point to several key, recognized features of the meaning of 'law'. The central one is the formal point above-that laws are general propositions which create legal duties. They had different theories about why these were duties.

The Western question took the form, "What distinguishing characteristic of penal law sets it apart from other obligatory universal statements?" Austin's classical assumption is that law is a ruler's command which he makes obligatory simply by threatening a specific, retributive punishment for violating that command. It specifically denies the Natural law view of a continuum of legal and moral obligation. Natural law treats penal laws as simply the particular and localized adaptations of that natural moral law. Positive legal theories stress the flexibility of posited law in contrast with the immutable nature of divine or natural law. They further require a realistic requirement of effectiveness. For a legal system to be in force is for a government using that system to exercise effective control over a territory.

B. Punishment. In most theories of penal law we find some argumentative link to retributive punishment. One possible inferential connection between the two is that punishment is only justified retributively. That is, we punish only for violating a specific, publicly promulgated law-one that the violator could have known in advance. The theory justifying punishment may treat this as a logical feature of the social practice of legal retribution and then further justify the whole practice on utilitarian grounds. We may tie desert-linked public standards of conduct to either punishment or reward. If we associate them with a system of nonstate institutional rewards, such as promotion, tenure, or salary, we call them 'standards'. If we tie them to a system of state imprisonment or execution, we call them 'laws'.

C. Publicity and Accessibility. Another feature of laws is their public accessibility and general application. The idea of law involves promulgation, publicity, and regularity. Natural law tries to solve the accessibility issue by appealing to the Aristotelian theory of universal access to reason. Law should be, in principle, something that those who are subject to punishment - the bulk of society-can know in advance. Formally The Law applies to everyone in the state. (It may apply to them, of course, by naming them as exempt from some laws.) We hesitate to call otherwise law-like systems "rule of law" when their administration fails to meet a minimal threshold of publicity, uniformity, and predictability.

D. Authoritative Determination Decision Procedure. Public codes drag along a famous semantic puzzle. How do we successfully project the

Chad Hansen 
denotation of a term from the cases we use in learning the word to the cases we meet in the future? Legal litigation typically takes the form: the law prohibits doing $X$, but mine is a case of doing $Y$, not $X$. A legal system with a fixed public code needs a workable solution to the problem of projection. Its defining solution is authoritative determination. We appoint people or panels to decide if the letter of the law applies to this person and her specific alleged action. ${ }^{17}$

Here one contrast of positive law and morality emerges. Morality does not have such an authoritative decision procedure. There is no fixed code; there are no performative moral authorities. ${ }^{18}$ In this contrast with law, we should distinguish morality proper from the accepted, positive group mores. General acceptance does not make mores moral. Advocacy by socially acclaimed sages does not make conventions right. This view of morality is central to Western ethical individualism. Individuals deserve fundamental respect as moral lawgivers.

E. Morality, Rationality, and Legitimacy. The relation of law and morality is a controversial area of Western legal theory. Moral arguments for the rule of law are common. Some familiar derivations justify law based on prudence, utility, or individualism. The positivist tradition usually insists on a radical conceptual separation of law and morality. It regards law as an independent, amoral posit lifted to the realm of duty only by the threat of punishment. The two prescriptive systems are conceptually distinct, but the traditional Western theory inferentially links the term 'law', like 'morality', to 'rationality'. Most obviously, our justification of legal duties and rights presupposes some normative claims about political legitimacy.

We may appeal to ethical individualism to justify the ideal of the rule of law. The powers will punish people who displease them. The human thirst for vengeance is a fact about human nature and about power. Law is a protection to individuals, to rational agents, because it makes the punishment predictable. Rational agents can plan courses of action that insulate them from official coercion. With legal institutions, people will know how to act and avoid coercive force. Our actual legal systems, of course, only approximate that ideal.

The important contrast is with rule of man, where the law is not specifically, clearly spelled out. Under rule of man, the authority decides based on his intuitive moral evaluation of you. That usually makes life more difficult for minorities, deviants, eccentrics, and women. Westerners regard any hint of rule of man as a criticism and evidence that the rule-of-law ideal has broken down. Again, when the system passes a threshold toward intuitive rule, we withhold the appellation 'rule of law'. 


\section{The Chinese Conceptual Scheme}

That thin theory of the inferential connections in Western legal theory should give us enough basis to study the Chinese case more carefully. There we will find many but not all of the elements. We will find them, however, distributed in different ways across the Chinese conceptual map.

One common feature we noted in the cases that scholars have offered for the law translation is the linking of fa and coercion or punishment. Graham, Ames, and Schwartz all agree that xing punishment originally referred to penal codes, and argue that fa came to duplicate xing. The ruler-coercion link also grounds the identification with Western positivelaw theory. Interpreters note, besides the ruler-punishment focus, the fa-jia ${ }^{\text {standardizers }}$ hostility to Confucian $/ i^{\text {ritual }}$. Modern interpreters join Confucians in treating that as hostility to morality. We also will see a suggestive hint of a concern with public accessibility accompanying Chinese discussions of $\mathrm{fa}$, which standard interpretations have largely ignored.

What we will not find is the formal, general syntactic concept of a law. Commentators seldom address this absence of any evidence of a sentential conception, of any attention to generalized prescriptions. ${ }^{19}$ The translator may reply that the Chinese concept of law is different. That admission (made in English) is hard to distinguish from saying that they do not have a concept of law. Concepts are logical individuals. If it is a different concept, then it is not the concept of law. Should we say it is a similar concept-like saying that Liberace is similar to Rubenstein? Then we will surely want to spell out the terms of the similarities and the differences. If their concept of fa is not even of law-like linguistic structures, then it is surely misleading to state that it means law. It will not do, in this situation, to say that 'law' is the closest term in English. 'Standard' is available and is the rival choice under discussion. It is an alternate translation that (unlike 'law', 'rule', and 'principle') need not entail its being a universally quantified sentential.

A. The Confucian Argument against Xing ${ }^{\text {punishment }}$. Let us first address $x^{\text {xing }}{ }^{\text {punishment }}$. Confucius gives a famous argument against $x i n$ punishment $^{\text {in }}$ the Analects (2.3). All the defenders of the orthodox meaning theory treat this argument as an argument concerning penal law. ${ }^{20}$ This raises two important points. First, there clearly are legal codes in China whether or not the conceptual scheme individuated them as we do laws. Second, there already was a word, xing punishment, which rival theorists took to refer to the codes.

The theory of the meaning of $x^{\text {ingunishment }}$ is a familiar example of a meaning argument based on the composition of characters from subcharacter units. The character is homophonous with $x^{\text {ing }}$ shape $^{\text {and }}$ uses 
刀 the same phonetic but with a dao $o^{\text {knife }}$ semantic radical rather than a feather radical. One popular theory is that the sense of the character incorporates the idea of carving, cutting, mutilating, or marking. We also find cutting off noses, ears, hands, and feet, as well as other marking techniques such as tattooing, to be common forms of punishment in early China. However, the same theory could equally serve to associate the character with the act of cutting or carving the codes themselves, that is, on bronze tripods or bamboo strips. The words of the code are themselves shapes. In either case, we will accept the implicit theory that xing punishment $r e f e r s$ to penal codes guiding punishment either qua themselves being carved or qua carving or marking people.

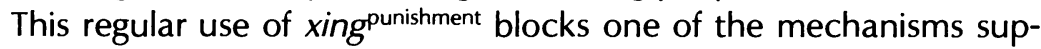
porters might have appealed to in explaining the alleged meaning change. If they wanted to refer to official systems of coercion or punishment using a public code, they did not need to narrow an existing concept. Classical philosophers already had a perfectly workable term with precisely the required reference. Confucius also makes similar points

政 正 using zheng-a character constructed of the homonym meaning to rectify plus a radical vaguely meaning to beat. Other available terms 製 令 used to describe official codes include $z h i^{\text {institutions, }}$ ling ${ }^{\text {orders: commands }}$, and 律 $\quad l \ddot{u}^{\text {ordinances }}$. So, there is no conceptual gap the filling of which would have required someone to narrow the meaning of fa.

Confucius uses a theory of names, not sentences. He certainly does not distinguish universal from particular or prescriptive from descriptive sentences. His question is "which body of discourse should we use in guiding social behavior?" not "how are penal universal prescriptions different from other universal sentences?" The unit of discourse that interests him is the ming ${ }^{\text {name }}$. So while $x^{\text {ing }}$ punishment denoted penal law, it did not have the same meaning - the same metaphysical structure. ('Featherless biped' denotes humans, but does not mean the same thing as 'person'.) Xing punishment played a different role in the network of inferences and available reasons a Chinese thinker would use in arguing for various social-political theories. ${ }^{21}$

In the West, despite wide differences in analysis and justifying theories, we assume we can justify the rule of law. Confucius argued with surprising vehemence against this style of coercive government and against its implicit analysis of the role of government. ${ }^{22}$ Punishment, he argued, gets social conformity at a cost. It undermines moral education and natural human development and dulls the inclination to spontaneous social conformity-shame.

Educational techniques achieve social conformity by reinforcing the social inclinations. Education, thus, leads to a stable, enduring solution because it relies on and exercises the social instincts. Official coercion, using laws and punishment, relies on, exercises, and therefore strength- 
ens self-interested calculation. Ultimately, therefore, coercive government is self-defeating. Mark Twain's comment captures the Daoist perspective on this Confucian argument: "Soap and education are not as sudden as a massacre, but they are more deadly in the long run." ${ }^{23}$

1. Public Guiding Discourse and Interpretation. The argument based on motivation combines with another traditional line of thought about $x^{\text {ing }}{ }^{\text {punishment }}$. It focuses on xing ${ }^{\text {punishment }}$ as a public, promulgated, carving. This ties xing ${ }^{\text {punishment }}$ to another inference relation characteristic of 'law'. Law is a fixed code that is public, open, and accessible to those we intend it to control. In some famous incidents in a traditional Confucian history, the Zuozhuan, Confucians criticize specifically the public promulgation of these codes. ${ }^{24}$ Their argument alleges that when the ordinary public knows what the $x^{\text {ing }}{ }^{\text {punishment }}$ are, they will lose their fear of authority. Why?

One possible reason is that if publicly accessible codes govern and control punishment, people can choose courses of behavior that assure freedom from punishment. The authorities will not punish them merely out of intuitive or moral disapproval. A linked reason might be that the framers of the code intended to produce an explicit code that the people could understand. It does not require interpretation by cliques of traditional, esoteric priests who regularly chant and study the ancient and obscure $i^{\text {ritual }}$. When officials feel like punishing them, explicit, easily understandable public codes give protection. They make it so that ordinary people can argue, against the authorities, that they have conformed to the code. Officials will become answerable; a simple, explicit, public code requires them to show that the alleged behavior really did violate the law. Coercion becomes harder to justify. "As soon as people know the grounds on which to conduct disputation, they will reject the $/ i^{\text {ritual }}$ and make their appeal to the written word." 25

We distort this ancient Chinese analysis, I suggest, when we apply our sentential conceptual scheme and interpret it as rules, sentence, or truths. Confucius was talking about a scheme of guidance. Western thinkers do routinely segment guiding discourse into units-rules (prescriptive sententials) or laws. Western tradition marks what it considers natural units of discourse ("complete" thoughts) with periods.

The ancient Chinese thinkers, however, never characterized the li as rules, as oughts, or as prescriptive sentences. When Confucius (or his ghostwriters) analyzed the formal structure of guidance schemes, they found ming $^{\text {names }}$. So, he presented the interpretative project as rectifying 名 正名 names.

The sages assign names to social ranks. (Rulers name people to these ranks.) These names determine which parts of $l i$ to use in guiding one's behavior. We act in accord with our rank and the rank of the "other."

Chad Hansen 
We behave properly toward each other only if we correctly classify each other. We must apply the name-rank-status apropos the $l^{\text {itualcode }}$ and the situation. The whole code fits names into a hierarchical social scheme and people should fit into these slots. Breaking this scheme into units where Westerners put periods was not an explicit part of ancient Chinese philosophical grammar.

The interpretative concern starts from the projection problem for words. As we saw, the form is "The code refers to $X$; how can one show that mine is not a case of $Y$ rather than $X$ ?" The Analects discusses the projection problem in a passage that links it to both punishment and liritual ${ }^{26}$ Rectifying names, according to this famous passage, would be the first measure Confucius would adopt if a ruler finally placed him in office (13.3). If we do not use names correctly, Confucius reasons, then we will misapply any form of guiding discourse. If authority does not rectify

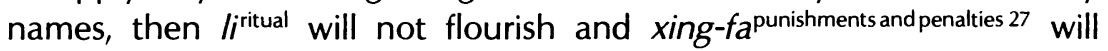

刑罰 "miss the mark." 28 This concern underlies Confucian worries about the rise of litigiousness, glibness, and cleverness-especially among people governed by published codes.

2. Hyper-traditionalism, Morality, and Rule of Man. This second argument, however, could become a minefield for Confucianism. Any formalized code is subject to interpretative dispute. The $l i^{\text {ritual }}$ is such a fixed code-though not cast on tripods. Confucius studied $l i$ in historical documents and taught from a book of li-like a book of etiquette. We thus call Confucius' teaching a 'positive morality' as we call law 'positive law'.

So one can use the projection problem to criticize published codes only at the risk of threatening $/ i^{\text {itual }}$ as much as law. The $/ i^{\text {ritual, }}$, as the passage implicitly acknowledges, is also a code and is equally subject to performance interpretation. ${ }^{29}$ The $/ i$ clearly led to disputes among Confucians about correct performance, about the degree of allowed deviation, about dealing with exigencies, and the borderline between names.

There is one distinction that gave Confucians a reason to use $/ i^{\text {ritual }}$ while rejecting positive law. Using $/ i^{\text {ritual }}$ confined the interpretative dispute to the ranks of the priest class. Confucians thus attacked public codes for their very publicity and general accessibility. Only ritual specialists - most notably those educated by Confucius and his intellectual heirs - could interpret the $/ i^{\text {ritual }}$. Only granting them that monopoly on interpretative authority could preserve their lofty status.

The other key difference is that self-interest is not similarly exercized in using $/ i^{\text {ritual }}$ in the way it is in using $x$ ing $^{\text {punishments. The combination of }}$ promoting selfish processing and glibness in pursuit of self-interest is what makes public codes of punishment objectionable. Such public 
codes undermine what Confucians would consider natural hierarchical mechanisms of social control. The first objection is to punishment's tendency to induce and to exercise selfish heart-mind processing. The second is that a public, legal code invites the general population to quibble about which term in the code applies to them.

The traditional story of Dengxi illustrates the outcome that worried Confucians. ${ }^{30}$ Tradition claimed that Dengxi's clever legalistic arguments, designed to escape correction, confused shi-feithis-notthis . Penal law systems reward clever disputation that exploits the inevitable loopholes and vagueness in any code. The constant need to fill these loopholes requires an equivalent cleverness. Specially trained disputers eventually will both write and interpret the laws. Given the tendency of law to strengthen self-interested calculation and weaken natural social instincts, the institution creates a dynamic that feeds on itself and grows out of control. You eventually have libraries filled with laws, an army of lawyers, and jails overflowing, and you will still be insecure in your streets. Eventually even your political leaders will say, "What I did may have been immoral, but it was not illegal!"

I call the two concerns about law the motivational concern and the interpretative concern. The interpretative concern requires the rectification of names so both $l i$ and xing can give reliable guidance to people. This interpretative concern reminds us of still another aspect of the theory of law - authoritative determination. Confucian attitudes and interests favor their being the interpretative authorities for all guiding discourse-moral or nonmoral. Adopting a nontraditional code undermines the Confucian justification for giving special interpretative authority to traditional scholars - to Confucians.

In my view, Confucius' claim does attack punishment, but he interestingly does not develop the interpretative argument by either attacking $f^{\text {standard }}$ or using fa to deal with the interpretative issue. The two occurrences of $f a$ in the Analects do not illuminate his view of either the motivational or the interpretative issue. If he has an answer, it lies in his mysterious concept of ren humanity $-a$ virtue the authorities who rectify names should possess.

The interpretative concern focused on $/ i^{\text {ritual }}$ was one factor that pushed Confucianism toward an innatist or intuition-driven version of their theory-Mencian orthodoxy. We can interpret any guiding code into performance in many ways. Once we have formulated that worry, it will appear that we have to rely on something other than the code itself to settle which interpretative performance is correct. A traditional, codebased morality lacks something. An authoritative performance intuition is the Idealist wing's answer to that lack. It purports to settle interpretative disputes about whose performance correctly follows the code. The 
idealist view in China assigned this role to the mysterious term ren humanity. It anchors the Confucian argument for the rule of man-substitution of the moral intuition of an elite class for explicit codes of behavior.

B. Fa in the Mozi. We first notice focused philosophical use of the character $\mathrm{a}^{\text {standards }}$ in the early anti-Confucian writers, in particular Mozi. Mozi used the term in a theory of interpretation that we can view as his proposed solution to the projection problem. Fa $a^{\text {measurementstandards }}$ are standards of language use that are accessible to people using only their eyes and ears. Mozi's approach to morality is via a revised guiding discourse content and these interpretative standards. He does not worry about the truth of moral theory. His scheme, like Confucius', treated words, not sentences, as the crucial bearers of linguistic guidance. ${ }^{31}$ $\mathrm{Fa}^{\text {measurement standards }}$ are guides to applying the words found in public guiding discourse.

In general, Mozi applies fastandards $t$ to language, but in particular he uses it for determining the linguistic content of the moral daoguidingdiscourse. A dao is a bit of guiding literature. Mozi needs first a standard that determines what "language" to include in public literature. The traditional code, he argues, is not necessarily right. We can justify a substitute, however, only if we have a standard to evaluate the traditional and the proposed new moral code together. Mozi's standard for selecting and 利害 interpreting the guiding code, the proper dao, is li-haibenefit-harm. This, he argues, is a natural (supracultural) linguistic distinction. It gives us measurable access to an objective morality. "The natural will is like a compass to a wheelwright or a square to a carpenter."

Thus Mozi's discussion of fa makes it more theory laden than mere 'standards'. Fastandards are publicly, objectively and naturally accessible, measurement-like standards. The prototype is a pair of contrasting terms. They are not, that is, rules - not universal sentential prescriptions. Mozi's appeal to $f a^{\text {standards }}$ contrasts explicitly with the elite intuition standard that is implicit in the Confucian theory of traditional codes and their practical interpretation. Tradition is not a fa, because all traditional language is equally permissible and traditional codes are subject to interpretative dispute.

$\mathrm{Fa}^{\text {objective standards }}$ should be reliably projectable standards for selecting some language and rejecting other language. Other paradigm $\mathrm{fa}^{\text {standards }}$ were measurements (plumb line, sunrise gnomons, carpenter's square). Therefore, a code that is clear and openly published would fall in the

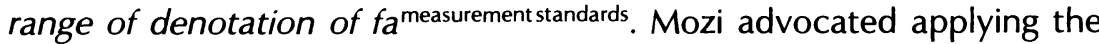

政 $f a^{\text {standards }}$ to the language used in xing punishment and in zheng administration. This is not because fa means law, but because we should have codes that Philosophy East \& West qualify as objective, measurable, public standards of behavior. 
1. Sentences and Guiding Terms. Mozi conceives of the debate between daos mainly at the name/distinction level. Still, he argues for a change in the entire code. Examining how he does this yields an interesting insight into the conceptual structure underlying moral debate in ancient China. We should, he argues, abandon the traditional $/ i^{\text {ritual }}$ and revise our conventional guiding discourse. Mozi proposes a new dao.

A dao is a scheme of names designed to guide behavior. The core cases are Confucius' social-role terms, names of ritual objects, and action classifications. These all guide behavior via being programmed in people -input, as it were, in social discourse and informal education. We analyze normal moral disagreement as cases where we apply names differently in interpreting the guidance from these codes. Chinese philosophers focus on opposite terms and treat the projection problem as a problem of where to draw the distinction between $X$ and not- $X$. The key

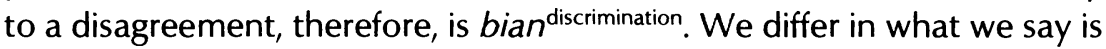

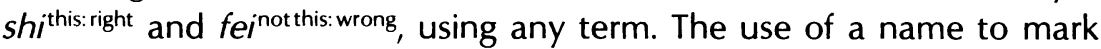
a distinction is the key step in applying moral guidance.

Mozi proposes the $l i$-ha $i^{\text {benefit-harm }}$ distinction as the standard to guide the interpretation of prescriptive language. He derives its ability to guide the ordering of terms in a dao from its function of guiding the application of terms. He addresses, for example, the issue of whether public dao should include you-ming havefate or wu-ming lackfate, $y o u$-shen havespirits or wu-

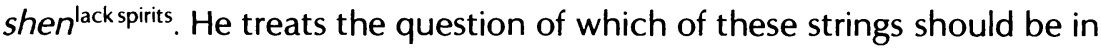
public discourse as calling for a projection-discrimination solution for

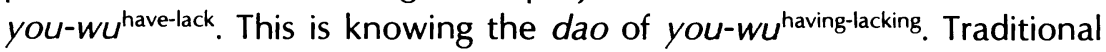
accounts have misconstrued this feature of Mozi's thought. They have treated it as an argument justifying belief in spirits and skepticism about fate. Mozi puts these points as examples of the proper way to use the you-w $u^{\text {having-lacking }}$ distinction in public guiding discourse. Making the distinction correctly is using the terms next to other terms correctly. Thus

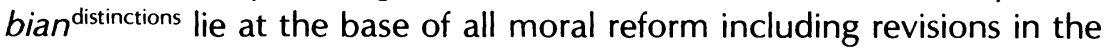
content of public guiding discourse-the dao.

Mozi's detailed theory mentions three $f a^{\text {standards }}$ of appropriate yan words:language. They are primarily standards for the socially appropriate application of terms. ${ }^{32}$ In one of the three versions of the doctrine, the word biao ${ }^{\text {gnomon }}$ replaces $\mathrm{fa}^{\text {objective standards }}{ }^{33} \mathrm{He}$ repeatedly likens $\mathrm{fa}$ to measurement gauges - the plumb line, compass, and measuring stick. We can clearly link this notion of a measurement standard for the application of an instruction set to the verbal use of $f a-$ to model, to emulate. One way to learn how to interpret a code in behavior is to emulate our parents or social leaders in their execution of the instructions.

This use of fa to represent measurement-like standards is common in this early period. Rickett, for example, identifies the same focus in the

是 非

利害

有命 無命 有神 無神

有無 有無之 道

辯

\section{言}

表 法

Chad Hansen 
doctrines attributed to Confucius' closest Legalist-minded contemporary, Guanzi. The foot rule, marking line, compass and square, beam and weight, peck bushel, and grain leveler are fatandards. 34 Guanzi could and did, therefore, consistently advocate both $/ i$ and $f a$. Confucius need not have been, and was not, critical of Guanzi for his attitude. Fa could easily complement, and arguably was necessary to, any traditional guiding scheme of names.

2. Standards and Moral Skepticism. Mozi rejected the li. He did so, however, not specifically on grounds of their vagueness but on moral grounds. Traditional codes may be morally wrong. To determine if they are moral, we must have a standard. Given his philosophical grammar, the standard will be the standard of language - the dao of terms. The standard he proposed was altruistic utility - general application of the $\mathrm{li}$ hai ${ }^{\text {benefit-harm }}$ distinction. The $/ i^{\text {ritual }}$ fails this moral test. It is wasteful for the society and harmful to the people.

Mozi's utilitarianism contrasts in an interesting way with that of Hume and Mill. He does not treat utility as the implicit standard of our existing morality - as an analysis of the meaning of moral. He proposes it instead as an explicit moral reform - a revision of conventional moral attitudes. He thinks we have a natural impulse to judge on li-hai benefit-harm grounds and he argues that the conventional Confucian morality should but does not meet that natural standard.

Understood as a proposal for moral reform, for changing the public dao, Mozi's position has a familiar philosophical hurdle. Any attempt

是 at moral reform proposes an alternative way to assign shithis:right and

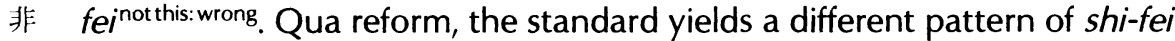
than do our acquired traditional attitudes. A traditionalist instinctively regards that erroneous assignment as prima facie evidence that the reform proposal is wrong. The reformer notes that this counterargument relies on the assumption that traditional moral attitudes are right, and thus begs the question. The traditionalist retorts that the reformer's arguments take his reform criterion for granted and, from the traditionalist's point of view, equally beg the question. This retort has even more bite against a Western utilitarianism. If the criterion does not yield outcomes we regard as moral, that is prima facie evidence that it is a bad analysis of the meaning of the word.

In this standoff, the traditional scheme has another advantage. It normally includes thick moral concepts that we apply or project onto the world with studied social consistency. We lack strict rules for their use, but native speakers typically have learned to apply them intuitively in consistent ways. The reformer cannot rely on that scheme of shared guiding intuitions. His proposals must be more easily projectable if they Philosophy East \& West are to give any guidance at all. It is probably no accident that moral 
revisionism in both traditions has been dominated by a standard that can be thought of as a calculus or a measurement.

Mozi presents his proposal as analogous to measurement with a gauge, not as a calculus. Ordinary people can apply the standard without needing an educated intuition or intensive exposure to the tradition. The gauge guarantees that people will apply the standard in a constant or reliable way in guiding behavior. We can't expect ordinary people to perform /iritual correctly, but they can measure a board with a ruler, draw a perpendicular accurately with a square, and find a vertical with a plumb. The analogous, measurement-like utility standard should be equally easily to project. The people should need only their eyes and ears to apply it.

Any moral reform requires such clear projectability before we can assess it. Still, as Zhuangzi delights in pointing out, mere projectability does not constitute a neutral ground for assessing moral reform proposals. Those who accept the utility standard think its outcomes are obviously right. Those who reject the basic standard think the outputs of utilitarian morality are obviously immoral. Given that the reform is less well entrenched in our acquired moral intuitions, the best we can hope for a moral reform is clarity, simplicity, and easy projectability. We cannot settle the question of its correctness without presupposing something else.

The Later Mohists continue to exploit this role of $f a$ in their more elaborate semantic theories. A fastandard, they say, is that which, in being like it, a thing is thus. To describe a thing with a term is to compare it to a standard $(A 70,71)$. Standards of similarity and difference determine the extent and limits of our commitments to apply words to things (A94-96). Thus $\mathrm{fa}^{\text {standards }}$ are crucial to our distinguishing daoguidingdiscourse and 道 guiding human behavior (A97-B1). ${ }^{35}$

So the original role of $f a^{\text {standards }}$ that we found in Mozi's thought is mirrored in the use Rickett found in the Guanzi and is refined by the analytical dialecticians. Fa are generally applicable to any guiding discourse - from morality to ritual, crafts, and penal codes. Quite clearly, what we call laws - publicly promulgated codes - may be instances of such publicly accessible standards, and we could use fa in punishment and administration. But the notion is a quite general one of objective measurement standards. They guide guiding discourse. All explicit law could count as fa but not all fa is law. So fa means law in the remote sense that mammal means cat-it may be included in its range of denotation.

\section{The Background of Han Feizi's Ethical Theory}

A. Daoist Skepticism. Daoist reaction to the Mohist-Confucian debate focuses on the insolubility of the paradox of moral reform. Mozi clearly Chad Hansen 
hoped that the natural $f a^{\text {standards }}$ of language would yield some objective dao, one that did not depend on acquired traditional or conventional moral attitudes. Laozi's analysis hinted at the claim that any dao based on language would presuppose some conventional standard. This, I suggest, is part of what a denial that there is any constant dao implies. Laozi could be taken to explain away Mencius' innate moral-feeling structure. These are another result of our having learned conventional patterns of making distinctions and using them in guiding action. We can occupy no presuppositionless starting point. Hence, we can find no objective, natural, or constant dao.

Another hope was that a standard would settle interpretative matters - questions of where to distinguish between $X$ and not- $X$. That hope, too, is dashed by Daoist analysis. Not only is it impossible to justify the choice of $l i$-haibenefitharm as the ur-standard against the rival Confucian traditional standards; even that standard raises its own problem of projection interpretation. Should we count purely material well-being as benefit, or should we include moral development? We need a standard to tell us how to project the standard, since it is itself a bit of language. Once we start down that road, it is not clear where it will end. Essentially, as Laozi argues, there is no constant dao because there are no constant names.

Zhuangzi noted that appeals to intuition are circular and selfjustifying. Anyone's interpretation will seem intuitively correct for him and those who share his perspective, and wrong for those who do not. This further undermines Mencius' appeal to a natural, instinctual moral intuition that happily turns out to coincide with traditional Confucian

是, 非 norms. Even the fool has a ruling heart-mind that shoots out shi and fei. A Confucian needs to appeal to something other than the built-in instinct of the heart to make a fool-sage distinction. An innatist must give some heart-independent reason to revere or model one's heart on the sage's heart. We need some standard to justify the claim that we ought to train the fool's heart to be like the sage's. The simple appeal to a natural, pan-human heart cannot justify such a choice.

B. Xunzi's Conventionalism. Xunzi reacted to the Daoist critique by a converse strategy to turn the apparent Confucian weakness into a strength. Since nothing could work as a neutral critique of traditions, the only "real" standard of the correctness of action guiding language must be that tradition itself. Xunzi turns the historical conventionality of the li ritual into a decisive consideration in its favor.

His best point in favor of this conservative moral conclusion lies in observing that the standard of correctness of language (names) is convention (tradition). Given that the question about the objectively correct 
the answer is that the correct use is the conventional use. The correct dao is the conventional dao. The standard of correct interpretation of the traditional dao is also conventional. The correct interpretation is the living conventional interpretative tradition.

The Confucian dao, therefore, is whatever the trained and cultured

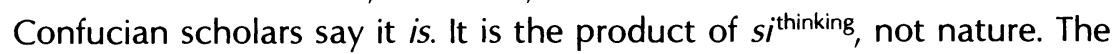
sage kings started the tradition, and, Xunzi insists, it makes no sense to say, that someone used a word correctly without appealing to that enduring tradition of usage. So for Xunzi, the $\mathrm{fa}^{\text {standard }}$ is the trained attitude of a traditional scholar - the junzigentleman.

Xunzi's use is, theoretically, the most radical deviation from the original theory of $f a$. Xunzi uses $a^{\text {standards }}$ almost ironically. Since there can be no neutral, objective, purely measurement standards, the only possible standard can be the junzigentleman himself-his intuitions and behavior. The interpretative inclinations of the trained scholar are precisely what Mozi or Guanzi would have contrasted to fa. Mozi's original coinage specifically opposed Confucian intuition. Scholarly intuition is the opposite of objective, measurable, publicly accessible standards.

C. Han Feizi's Amoral Authoritarianism. Han Feizi, himself a ruling noble, would hardly fail to notice that Xunzi's doctrine amounts to a plea for the authority of a scholar-elite. Allowing the code of $l i$ itual to be the guiding dao of the society entails allowing the intuition of the scholar special authority. That authority, in Han Feizi's view, threatens to emasculate the ruler. Still, he accepted his teacher's assumption that if one accepts the traditional code as the guide to behavior, rule by scholars was the only allowable conclusion. His only recourse, thus, was to reject the authority of tradition.

Authority, he argued (borrowing from Shendao), is a matter of situational, chance positioning - not of moral excellence or other cosmic approval. From the moral point of view, as Shendao noted, it is an accident who is the authority. Still, it is the person in authority who guides others in society. He does this because he has the power, charisma, and position to do it, not because he is an expert in the use or theory of language. The key power in the hands of a political authority lies in his control of the two handles - reward and punishment.

Han Feizi's political theory simply accepts the authority of the king; it is not a theory of legitimacy. Beyond reducing the concept of legitimacy to circumstance, his theory is not a moral or political philosophy. It is a strategy, addressed to the king, about how to preserve this power. In the power struggle, Han Feizi saw one main source of danger-and it was not the people. The threat to a ruler comes from the scholarbureaucrat. The doctrine that made that scholar-bureaucrat powerful was his self-appointed role of directing public discourse.

Chad Hansen 
Confucians, especially, draw Han Feizi's' wrath. They seek power by claiming special access to the traditional code of rulers of the past. Applying their code, as Xunzi argued, required elite and esoteric scholarly, historical knowledge of past literature. They manipulate kings with their erudition and mastery of these elaborate traditional systems dictating a ruler's proper behavior. The king's survival depends on ignoring them. He must take the control of public discourse out of the hands of scholars. Thus he must be a reformer-not for reform's sake, but to prevent his power draining to experts in traditional discourse.

$\mathrm{He}$ is also not a philosopher like Mozi. Han Feizi accepts the nihilistic conclusion that there is no natural, neutral, or constant guide for moral reform. Pragmatically, however, the state needs a single, coherent discourse. Justifying its content, beyond such pragmatic concerns, is neither necessary nor possible. Even raising the question invites philosophers to replace historical-literature experts in the power structure. All the ruler should do is arbitrarily identify one clear body of guiding discourse and reject all rivals and all philosophical bian ${ }^{\text {distinction-dispute. He forbids both }}$ disputation about what that guiding discourse should be as well as any identification with past discourse. Both threaten to transfer authority from the ruler to the scholarly bureaucracy - the advisors.

In the Han Feizi, thus, we do get a familiar aspect of legal positivism-a specific and strongly stated antagonism to $/ i^{\text {ritual }}$ and $y i^{\text {morality }}$. Han Feizi formulates this as an opposition between $l i$ and $f a$, but we can now see that the familiar opposition has a quite different explanation. He is not a legal positivist with the familiar Western views about the separation of law and morality. His is simply the next stage in the dialectic leading from Confucius to Mozi, the Daoists, and his own Confucian mentorXunzi.

Han Feizi draws some comfort for his amoral realism from Daoism. ${ }^{36}$ The key Daoist point is that we cannot fix the standards of discourse without begging the question. Moral dispute has no objective solution. In place of the Daoist's tolerance of ambiguity, however, he has a Confucian's (and ruler's) fear of anarchy. He concludes that a focus on philosophical morality leads to relativism, skepticism, and, therefore, disorder. ${ }^{37}$ Best to dispense with such talk and stick to clear, public standards of behavior-even if they are arbitrary. Given the ruler's position and perspective, he can and should adopt and enforce an expedient guiding discourse. He does not need any claims of sage-like moral virtue.

His opposition to li, his antagonism to moral and semantic debate, and his fondness for the promulgations of the ruler do not signal that Han Feizi has changed fa's meaning. There are parallels between the Western debate and the debate going on in China in Han Feizi's time. They are, however, different debates. Alleging that Han Feizi has inexplicably joined a remote Western debate does not make his position any clearer. 
Han Feizi does not make fa refer only to sentential prescriptions backed up by punishment. We hardly need to make this assumption to explain his reasoning.

We can motivate his theory using the concept of objective standards of language use. He relies on the basic point Mozi first made about the concept. He joins the pre-Xunzi theorists in opposing fa to an elite's intuition. He opposes any code of conduct that drags such a nonobjective standard in its wake. This is not because he has a philosopher's concern with answering ultimate questions. Disputation about standards invites philosophers and scholars into the circle of influence. He opposes philosophy and intends this to abolish it.

On the present analysis, what happened in ancient China is this. Han Feizi, still a Xunzi-like authoritarian, splits with Xunzi (the Confucians) on one issue. They otherwise both agree that we need some way to solve the problem of interpretative or justification standards. Han Feizi rejects Xunzi's solution. It erodes the original point of fa. Conventionally cultivated intuition is not in the spirit of fa. Any code that requires such an intuitive or esoterically educated standard of interpretation is also not a fa. We should only call a publicly accessible code with clear measurement-like connections to punishment and reward fa. Thus $\mathrm{fa}^{\text {standards }}$ is not the name of the ruler-generated code, but of the underlying ideal of measurement-like explicitness. Only that feature justifies adopting such an explicit code rather than the traditional code. A look at fa jia $a^{\text {standardizers }}$ theory, from Guanzi and Shangyang to Han Feizi, confirms that all of them thought of fa as important in reward, advancement, appointment, and job evaluation, as much as in guiding punishment. Han Feizi and Xunzi do perfectly agree on the appropriateness of draconian punishment; they are equally enthusiastic about physically mutilating and crippling those they judge to be miscreants.

The semantic point, in conclusion, is that Chinese thinkers come to see penal codes as instances of $f a$. That result does not justify saying fa's meaning changed. They can cite the fact that published codes are fa in their reasoning, using the prior meaning of fameasurementstandards. In all this evolution of political and moral theory, no one in the Chinese tradition had developed a notion of either a sentence or a sentence in universal law-like form. In that key respect, they simply do not use any counterpart of our formal, syntactic notion of law. They, however, clearly already had terms for promulgated codes of behavior-and it is not $\mathrm{fa}^{\text {standards }}$. Fa are mainly required to interpret these codes. But Mohist and especially Daoist analyses have led to skepticism that we can separate discourse and interpretative standards. The standards are merely more discourse that guide behavior-including speech and evaluative behavior. Thus public discourse is now regarded as fa-as the measurement-like standard guiding behavior in general.

Chad Hansen 
A. No Clear Commitment to Rule of Law. Han Feizi's success as a writer probably owes more to his rich stories than to his reasoning. A random selection of Han Feizi's numerous stories reveals very little of anything we would recognize as a principled commitment to something resembling the rule of law. On the contrary, a typical range of stories describes rulers executing people for simply passing water or advocating Daoism. Neither the ruler nor the narrative cites any law, any stipulated punishment, any basis for the legitimacy of the ruler's arbitrary whim. Other stories describe a king's angrily ordering the instantaneous amputation of his beautiful concubine's nose when she offends him by wincing at his bad breath and body odor. He holds no trial, cites no law, appeals to no prescribed punishment. The punishments are executed on the spot with relish and at the ruler's whim. Han Feizi cites these cases with apparent respect and approval. ${ }^{38}$

These stories do clearly illustrate Han Feizi's approval of draconian punishment in enforcing and enhancing the ruler's otherwise arbitrary, accidental occupation of a position of authority. This celebration of frequent resort to cruel punishment is what our commentators have confused with a commitment to rule of law. It is, of course, precisely the opposite. It is the familiar Confucian assumption of special authority narrowed to a class of one instead of merely to the privileged, educated adviser-bureaucrats. It is a paradigm case of the arbitrary, intuitive, unanswerable rule of man. These stories illustrate nothing better than Han Feizi's theoretical identification with the interests, whims, and point of view of the ruler. His theory of $f a$ is motivated almost totally from the ruler's point of view. Very occasionally he gives general moral arguments or considerations drawn from some broader social perspective, but these are sporadic slips in his rhetorical strategy.

B. The Difficulties of Language. By contrast, the key theoretical theme throughout the Han Feizi is the unreliability of language. Han Feizi motivates his stern attitude mainly by worries about interpretative or linguistic anarchy. He observes that traditional doctrines such as Confucianism and Mohism split into incompatible interpretative wings. ${ }^{39} \mathrm{He}$ regards with horror the Daoist possibility of reversal of opposites. ${ }^{40}$ He says Confucians, Mohists, and other philosophers have twisted terms such as

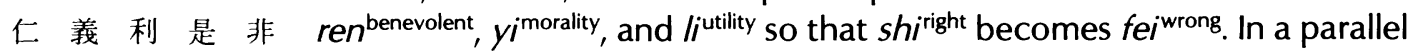
way, people interpret status terms or role names in distorted ways. The result is that the world ends up praising and denigrating, he laments, the wrong kind of ministers. ${ }^{41}$

Han Feizi follows the tradition consummately in regularly justifying fa

言 知 讋

法

Philosophy East \& West via its influence on $y a n^{\text {language }}, z h^{\text {knowledge }}$, and bian ${ }^{\text {distinction-dispute }}$. His reaction to the dialecticians clearly reflects the influence of Xunzi. The way to

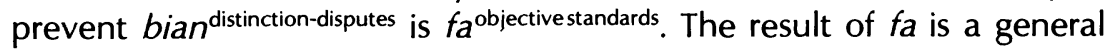


impact on the content of discourse and its relation to action. "Thus, regarding people within the borders of the state, their language and conversation will be guided by $f^{\text {standards }}$, their behavior will be resolved into practical accomplishment." 42

Language is particularly objectionable when in the mouths of philosophers, moralists, and analytic dialecticians. In the chapter titled Nan$y^{\text {difficult-language }}$, he recites a long series of such analyses of how language gets distorted. He concludes that the basic problem lies in an essential feature of professional political discourse: one has to be a worthy or a sage to understand it properly. ${ }^{43}$ Further, he traces disorder to the tolerance of rulers in allowing the existence of incompatible daos. There should be only one guiding discourse and one standard of interpretation. ${ }^{44}$ We should publicize the words that the ruler shis and stop those that he feis. ${ }^{45}$

1. Interpretative Motivations. Han Feizi's analysis involves a theory of how the $x$ h $^{\text {heart-mind }}$ executes its interpretative function. He denies that Xunzi's ideal of the empty and still heart is realistic. The heart-mind, he observes, inevitably calculates. Like Mozi, he regards the preference for $l^{\text {utility }}$ as natural-even inevitable, but it is not for neutral or universal utility. In its interpretation, he insists, the heart inevitably skews the outcome to the perspective it occupies. Even parents calculate their own interests in raising children. As our perspective changes, as we adopt different roles and positions, we change our interpretation of appropriate conduct. This comes closer than anything in Xunzi or earlier to a theory of natural evil in the heart. ${ }^{46}$

In particular, it is the nature of position that $c h e n^{\text {ministers }}$ must compete with the ruler. They will interpret moral guidance, orders, the expectations of their office, and so forth in ways that benefit those in their position, with their name, their rank, and their status. The king must reduce the space for such intuitive, interpretative manipulation to its practical minimum.

Ministers inevitably incline to interpretations that benefit their school or clique. The ruler thus needs measurement-like standards for dealing with appointment, promotion, and dismissal. The danger to the ruler specifically is that positional interest cliques will form among advisors who will recommend others from their clique. Thus the king cannot rely on words unless they are governed by clear, public, measurement-like standards. Han Feizi stresses the special importance of appointing and dismissing on objective, result-oriented standards. The ruler should avoid any other evaluation of worth especially of moral character-again including even his own intuitive assessment.

His theory of how to control language appeals regularly to the contrast of public fameasurement standards and siqu privatetwistings $^{\text {siyan }}{ }^{\text {privatelanguage }}$, and sixing privatebehavior. The opposite of $f a$ is not morality but partisan reason-

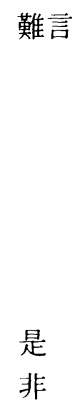

法 私曲 私言 私行

Chad Hansen 
ing, subjective intuition, scholarly cliques, and interpretative traditions. ${ }^{47}$ His special target, therefore, is $l i$ ritual , which he declares "empty sounds." The scholar-bureaucrats who interpret it mold it to their own interest. Wherever li emerges, he says, there is profit.

As Tang Jun-yi puts it, Han Feizi doesn't use fa to make people be good according to the world's antecedent idea of good. He uses fa to fix

是非 what is shi-fei. He cites Han Feizi's aphorism that the fa that prevents treachery first prevents it in the heart, then prevents it in language, and finally, prevents it in affairs. ${ }^{49}$

$\mathrm{Fa}$, thus, is not merely standards, but public, projectable, objective, constant, reliable standards of language use and interpretation. Accordingly, fa is conceptually independent of $x$ ing punishment. Legalists do disagree with Confucius (but not Xunzi) on punishment. They deny the psychological theory that underlies the Confucian strategy for educational social control. People are already skewed to favor their own position, and punishment is necessary for motivation. That point, however, is argumentatively separate from the dispute with Confucianism about standards.

Standards are necessary for the clarity and reliability of all forms of social guidance. ${ }^{50}$ Standardizers see the interpretative problem but reject the special, pleading Confucian solution to it. Their objection to Confucian standards is that they are intuitive, accessible only to the educated elite, and too malleable to their partisan purposes. They are neither objective nor measurable, and, worst, they undercut the king's authority. The measurement standards must neutralize the heart's intuitive ability to skew words and language in its calculations and interpretation.

2. Fraud and Deceit. The ruler cannot even rely on his own reactions to situations in making his judgments. Clever ministers can dazzle the ruler with their erudition and manipulate him using his own biases. To prevent this, even the ruler must be guided by unskewable $f a^{\text {standards. }}$. The standards, therefore, cannot be merely his desires or whims. They must yield some measureable good to whoever occupies the role of ruler or some good to the state. The $f a$, thus, are not merely the ruler's desires, published and backed by punishment. They are measurements that allow the ruler himself to avoid the trap of interpretative subjectivity and the word-anarchy that allows ministers to deceive him about their worth.

Han Feizi quite frequently proclaims that fa prevent the ministers from deceiving the ruler. "If one has regulations based on measurement standards and criteria and apply these to the mass of ministers, then that ruler cannot be duped by cunning and fraud." 51 Patently, laws, by themselves, cannot keep advisors from fooling or deceiving their ruler. No obvious inferential connection runs between the rule of law and being able to deceive the king. ${ }^{52}$ Laws, as Chinese tradition understood from 
insulates a ruler from duplicity is measurable standards against which to weigh their words.

The purpose of $f a$ is to deal with the confusion and doubt engendered by interpretative anarchy. The ruler needs $f a$, Han Feizi argues, to clarify distinctions in the relation of ruler and minister..$^{53}$ If $\mathrm{fa}^{\text {standards }}$ were simply laws, it would hardly explain this role of fa in Han Feizi's scheme. The null hypothesis not only can explain it, it explains it better.

Schwartz accurately identifies what he calls the fundamental issue dividing these two schools. Legalism stands for "a vision of society in which 'objective' mechanisms of 'behavioral' control become automatic instruments for achieving well-defined socio-political goals." This is correct. It shows that retributive legal constructs are only one aspect of the strategy of using fa. Graham, too, gets close to an important point when he says that Legalism diverges from Confucianism on whether the fa can work "of themselves." I take this to involve the Legalist claim that fa should work without scholarly intuition and authority.

If that is correct, then the Confucian $l i$ is in one respect surprisingly more like our concept of law than is Han Feizi's fa. Mohists and Legalists intend fa to work without authoritative decision making. Fa should be mechanical-self-interpreting. There are people whose job is to explain the fa to people, but not to determine if the fa apply to this case or not. The $f a$ are the standards ministers should use to make that kind of determination. In theory, $\mathrm{fa}^{\text {standards }}$ should not themselves raise any interpretative problem. The Confucian (Xunzi) position is that /iritual should guide society, and interpreting that requires scholarly intuition. Cultivated, scholarly intuition is the only fa.

The choice is between guiding human behavior using (a) measurementlike standards that anyone can apply using their eyes and ears and (b) a code that requires the intuition of the scholarly elite. Fameasurementstandards carves the issues differently from the way the Western debate did. On the one hand, Mohists and Standardizers stand against the intuitive pretensions behind the rule of man. On the other hand, they reject the use of authoritative determination as a decision procedure for $f a$. The $f a$ are a self-administering decision procedure. They are measurable, published, and accessible and are intended to guide ordinary people directly.

What is called "wisdom" consists of subtle and unfathomable doctrines. Such subtle and unfathomable doctrines are difficult even for men of highest intelligence to understand. If what men of highest intelligence find to be difficult to understand is used to become $f a^{\text {standard }}$ for the people, the people will find them impossible to understand. ${ }^{54}$

C. The Struggle between the Ruler and His Ministers. Han Feizi obviously assumes that the danger to the ruler comes from the high ministers, not from the people. He is obsessed with how ministers can (1) come to

Chad Hansen 
control a ruler and (2) borrow and eventually drain his power. Commentators recognize that interest especially in their accounts of shu statecraft, $^{\text {, }}$ and they note correctly Han Feizi's insistence that shu will not work

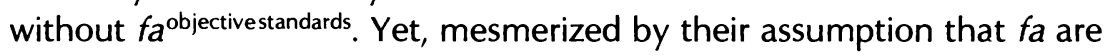
draconian laws, we continue to treat $f a$ as designed to control the ordinary people. Treating fa as law blocks a satisfactory account of the reasoning link between $f a$ and the control of high ministers. I have argued above that it provides no appropriate reasoning link between fa and preventing deception, fraud, and other language-based ways that ministers control the ruler. ${ }^{55}$ Here the identification distorts the natural theoretical relations of the famous doctrine of xing-ming punishment/shapename.

刑名 The doctrine of xing-ming, like Confucius' original theory, treats status or institutional names as guiding behavior. In a telling case, Han Feizi shows how the term-based technique for controlling ministers works. A captain whose title was not dresser thoughtfully covered up the ruler while he slept. Both the dresser and the well-meaning captain were punished for disordering names. ${ }^{56}$ Notice again that we find no citations of statutes, rules, or commands-but we can consider this an example of $f a$. The official has a name and there must be standards for interpretation of that name in guiding his behavior.

The point of the example is that the king punishes him although he intended the king's well-being. He did not stick to the formulated pattern of behavior signaled by his name. Fa, here, still represents noninterpretative standards for the application of names, not the ruler's desires. If, as the text indicates, ${ }^{57}$ xing-ming punishment-name is part of $s h u^{\text {methods }}$, 術 then this incident explains why shumethods cannot work without fa objectivestandards for nameuse.

1. Lack of a Retributive Theory of Punishment. In guiding the execution of reward and punishment, Han Feizi's reasoning is invariably more utilitarian than retributive. He often talks about punishment-both as a way of getting the standards adopted and as an activity that we should guide using measurement standards. Still, he rarely directly links a specific punishment as a matter of desert to instances of violation of a specific prohibition. He does not, that is, employ the normal, legalistic retributive instinct about the severity of punishment. He treats punishments and rewards as independent general strategies either for benefitting the ruler, for enhancing his power by instilling fear, or for achieving some more vague balance of good over evil actions.

Han Feizi more frequently advocates making both punishment and reward unreasonably brutal than for making punishment rationally proportional to harm and responsibility. His arguments here are overwhelmingly consequentialist. Harsh punishments and rewards more effectively guarantee the desired outcome. "When rewards are generous then what 
[the ruler] desires to achieve will be speedily achieved; when penalties are severe, then what he desires to prohibit will be speedily achieved." ${ }^{\prime 58}$ The goal of punishment, he tells us repeatedly, is to end punishment, not to restore some deserved moral balance.

I do not dispute that Han Feizi approves of punishment; what is relevant are the details of the relation of a punishing attitude and $f a^{\text {standards }}$. Mere fondness for mutilation cannot be evidence of a commitment to the rule of law. There must be some conception of punishment as a retributive response to violations of specific laws. Han Feizi does not justify punishment as retributive-as a direct consequence of breaking a specific law. His relish at stories of punishment counts more against than for the conclusion that he has a commitment to the rule of law. It does not support any case that fameasurementstandards has come to mean law. The most commonly given reason for thinking it does baldly begs the interpretative question in the now familiar way.

Only the prior conviction that fa means law makes fa and punishment go hand in hand for Han Feizi. Otherwise, we would notice that talk about $\mathrm{fa}^{\text {standards }}$ focuses on the projectable, measurable, nonintuitive nature of the standards used in all parts of the social guiding mechanism. We should apply fa in penal mechanisms as we do to all other guiding discourse. Han Feizi, however, does not conceptually limit fa to penal codes or to the application of punishment.

2. Fa and the People. The hypothesis that $f a$ is law also gives an unsatisfying explanation of Han Feizi's and Shang Yang's joint claims that $f a$ reduces punishment and pacifies the people. Treating fa as measurement-like standards for interpreting guiding codes does give an explanation of both. It does so especially when combined with the view that these statesmen intend the fa primarily to control the officials. Han Feizi argues, "The great ministers find the fa $a^{\text {standards }}$ odious and the little people dislike order." ${ }^{159}$ This suggests he directs control by fa primarily at the ministers, not at the people.

Han Feizi credits Shang Yang with the development of fa as a technique of rule. In the alleged fragments, Shang Yang justified the publicity condition for guiding discourse in an interesting way. It is surprisingly sympathetic to the people's point of view. "The multitude of people all know what to avoid and what to strive for; they will avoid calamity and strive for happiness, and so govern themselves."60

Shang Yang proposed an elaborate system to spread knowledge of fa. He puts the moral argument about as well as anyone could without appealing to some doctrine of individual rights. It reminds us of the flip side of the argument above that we saw earlier Confucians offer. "Government officials and people who are desirous of knowing what the $f a$ stipulates shall all address their inquiries to these fa officers, and they

Chad Hansen 
shall in all such cases clearly tell them about the fa and mandates about which they wish to inquire." His stress on this point goes right to the heart of the Confucian scholar-official's access to privilege and power. "Since the officials well know that the people have knowledge of $f a$ and orders, ... they dare not treat the people contrary to the $f a . . .{ }^{\prime \prime 1}$

Shang Yang's position, therefore, is antibureaucracy, not antipeople. It is a precursor of Han Feizi's attack on the power of the advisers.

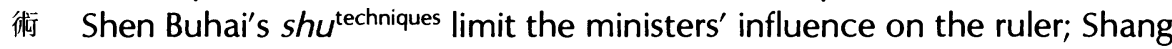
Yang's fa controls their power over the people. If they have to abide by measurement-like standards in punishing and rewarding, they cannot arbitrarily reward loyalty and punish political enemies. This disrupts one way they could build a power base. Han Feizi regards both techniques, therefore, as necessary for the ruler to preserve his power.

Han Feizi, like Shang Yang, repeatedly alleges that $f a^{\text {standards }}$ will reduce punishments and eliminate the need for pardons. If fa simply means penal laws, then $f a$ institutes punishment. We could hardly reduce penalties by setting up the institution that creates them. To make sense of this feature of the argument, we need only remember that xing punishment is conceptually independent of $f a$. Then we can see that clear measurement standards, easily applied and widely known, will reduce punishments. People can accurately gauge what will bring the wrath of officials on their heads. Armed with that knowledge, they then can and will avoid it. They will choose to avoid punishment when they know clearly what will and will not bring it. If punishment is dependent on the moral intuition of a scholar-official, as Confucians hope, the people will have no reliable idea of how to avoid it. Severity of punishment without clear standards cannot help people evade punishment.

Both Han Feizi and Shang Yang also consistently maintain that $\mathrm{fa}^{\text {standards }}$ pacify people. Again, if fa means the practice of draconian punishment, this would make no sense as a reason for $f a$. The regularity and predictability of the system, on the other hand, could pacify people. The fa gives them safety and protection against the officials.

If we pick an elite cadre of professors of ethics and let them dish out punishment whenever they think we are bad, then anyone of a different class or type with different outlooks and attitudes than those professors will be unsafe. We have to curry favor with that class rather than follow clear guideposts. We never know when someone might slander us, or we might fall out of favor or incur their dislike in some other unpredictable way. If we assume that $f a$ are not the source of punishment, but clear standards controlling them, the picture comes into focus. In being clear, measurable standards for the imposition of punishment, fa give the people a measure of protection against the arbitrary application of $x^{x i n g}{ }^{\text {penal codes }}$. Still, Han Feizi's celebration of punishment does not require 
their being fa. Conversely, his support for fa does not rely only on their use to guide only punishment.

D. Evidence of the Broad Sense. Han Feizi's use of $\mathrm{fa}^{\text {standards }}$ confirms repeatedly what Graham said. Han Feizi uses $f^{\text {standards }}$ in a broad sense. He speaks of fadu $u^{\text {standard measures; }}$ faling ${ }^{\text {standard orders }}$, fash $^{\text {standardtechniques, }}$ faliang standardmeasurements, and so on. Of these, faling ${ }^{\text {standardorders }}$ would argu法度 法令 法術 ably come closest to denoting a class of the ruler's commands. That, however, simply confirms that $\mathrm{a}^{\text {standards }}$, by itself, still has the wide sense.

As we noticed, Han Feizi identifies Shang Yang as the source of his doctrine of $\mathrm{fa}$. So, according to the causal historical theory of meaning, we treat him as intending to use it of the artifacts Shang Yang did. Schwartz, too, accepts this identification and then clearly describes $\mathrm{fa}$ not as law but as a standardized program of social institutional change. ${ }^{62}$ Penal law, he there allows, is merely a subclass of fa.

Now, the question is, do the Legalists ever confine the use of $\mathrm{fa}$ specifically to penal laws? Some laws are clearly instances of fa. Still, once we understand the relation of meaning and reference, we have no reason to treat even the most explicit case of calling a direct statement of a law ' $f a$ ' a case where the meaning has changed. Using fa to refer to a law or laws is not using ' $f a$ ' to mean 'law'.

One of the most cited cases to support the meaning-change hypothesis is Shang Yang's military promotion rule. Han Feizi cites approvingly as an example of $\mathrm{fa}$ a regulation that ties rank and salary increases specifically to the number of enemy heads cut off in battle. ${ }^{63}$ Notice two points about this frequently cited case. First it is a case of a reward, not a punishment. Second, the salient feature is not its law-like, sentential character or its being a command. What is important is its measurement-like character. It does not require intuitive or moral evaluation to determine the size of the promotion. It applies with measurement-like objectivity. In this, Tang concludes correctly, Han Feizi and Shang Yang are "exactly following Mozi."64 Neither narrows the meaning of fa ${ }^{\text {objective public standards. }}$

E. Semantic Summary. So we conclude that throughout the classical period, fa consistently means measurable, publicly accessible, standards for the application of terms used in behavior guidance. Daoist analysis shows that such standards of language are themselves examples of behavior guiding language. Legal codes fall within the scope of reference of the term because legal codes are explicit, published, and accessible. Han Feizi and Shang Yang intend them to be as self-interpreting as measurements. They specifically exclude reliance on cultivated, elite intuition as a source of guidance. Far from showing that fa has changed its meaning, this development conforms even better to the original meaning analysis.

Chad Hansen 
Not only can the null hypothesis explain the text's reasoning, it makes it sound reasoning.

I have argued that the full justification required of a meaning-change theory would be hard to supply. The crucial semantic point is this: wherever a translation yields a statement that is either true or intelligible when we translate $\mathrm{fa}$ as 'law', that statement also will be true or intelligible when the translation is 'standards'. Conversely, however, in many (proba法家 bly most) places throughout fa-jia ${ }^{\text {standardizer }}$ texts, translating fa as 'law' produces sentences that are false or difficult to make sense of on their face. We must attribute implausible or supernatural beliefs about law to the writers to make them plausible.

Objective, public, measurement-like standards for applying names can plausibly make it hard for clever ministers to lie, for glib talkers to take people in with sophistries, prevent evil and deceit, prohibit error and prevent selfish motives, correct faults of superiors, expose error, check excess, and unify standards. ${ }^{65}$ How can laws achieve any of those outcomes? The supposed answer is we pass laws against such things and punish them. That solution, however, assumes that we have objective standards to use in applying the laws. The answer, in other words, ignores the classical problem that drew everyone's attention from Confucius to Han Feizi-the difficulties of interpreting language.

Semantically, nothing in Han Feizi's use could require us to adopt the hypothesis that the meaning of the term fa has changed. The hypothesis fails to explain the persuasive force of any of his main arguments for fa. It, on the contrary, detracts from the persuasive force of most of them. It does not capture the inference potential of the character. Han Feizi does favor using punishment to get the fa adopted. He favors punishment for motivating nearly all parts of his political program - as well as for anyone who wounds the king's sexual ego or otherwise ignores his instantaneous whims. Han Feizi's theoretical analysis of the political problem of rulership is that people naturally incline to private interpretation. We have to guide and motivate shared, public standards. Han Feizi's theory of how to motivate the adoption of publicly promulgated standards does rely on the threat of punishment. Still, he shows depressingly minimal attachment to the rule of law and lacks any obvious appreciation of the retributive link between law and punishment. That makes his bare fondness for and reliance on punishment irrelevant to the issue at hand.

Rejecting the meaning-change hypothesis does little morally to rehabilitate Han Feizi. (It perhaps does more to rehabilitate Shang Yang.) Han Feizi still does not become a democratic liberal or a kinder, gentler punisher. It does, however, clarify the nature and force of his reasoning, separating him especially from Xunzi's Confucianism. The meaningconsistent hypothesis ties his views to other assumptions permeating 
school of names, and Xunzi. Understanding Han Feizi requires no radical claim that he is speaking a different language or missing the point. There was communication between Xunzi and Han Feizi. Han Feizi opposed conventions and was against using the junzigentleman as the interpretative standard. This position is utterly consistent with the normal, established, constant philosophical meaning of fa.

\section{NOTES}

1 - Ames (1983, p. 228 n. 12), contrasts Zhuangzi's allegedly Natural Law theory with the Legalist's positivism. Schwartz treats the Legalists as social scientists (1985, p. 348), and Graham cites Schwartz with approval (1989, p. 269). Clearly there is a factor here of thinking of Legal Positivism as the rational or scientific view of laws. In principle, we could take fa to mean law while treating theorists as Natural Law theorists or any other theory that we would count as a theory of law.

2- Hansen 1985 and also 1992, pp. 14-26, 35-53.

3 - The purpose, as we noted above, may be flawed. Perhaps we should give it up. Or there may be some more scientifically respectable way to achieve it. We have avoided these questions, but only provisionally. We carry on the debate in the existing terms - for now.

4 - As we noted above, the common $\mathrm{MCH}$ theories entail that the first Daoist or the first Legalist made an egregious error in his use of the term. If there is an existing meaning, the theorist cannot treat the second meaning as existing until the mistake becomes a common practice. Since the term has a preexisting meaning, the first use that deviates from it must be a mistake. The $\mathrm{MCH}$ theorist should explain why the rest of the community did not detect and correct the mistake in the normal way.

5 - In the present case, for example, I suspect that fa does change meaning when translators used it as one of the translations of dharma in Buddhism. This automatically imports a new set of conventional inferences to other concepts in Buddhist theory. I have not examined whether the general use of fa changed enough after the invasion of Buddhism to support the claim that it changed meaning in non-Buddhist use. If there is a comparative-advantage case for the claim that it did come to mean law and if dharma is correctly or accurately translated as law, then this event could explain when and how fa changed meaning.

Chad Hansen 
6 - Lauren Pfister (1991) has drawn attention to the use of some of these appeals in the early missionary justifications of their meaning hypothesis designed to show that Chinese were monotheists and had a word for God.

7 - Hansen 1985.

8 - Schwartz 1985, p. 321.

9 - lbid., p. 322.

10 - Ibid., p. 323.

11 - Ibid., p. 338.

12 - Graham 1989, p. 275. Graham conforms to the orthodoxy in blaming Han Feizi for the meaning change. He treats the assumption that $f a$ requires the moral intuition of the cultivated gentleman as the standard view which Han Feizi revises. I will argue below that it is only the view of Xunzi. We should not ignore the Mohist, Later Mohist, Daoist, and Guanzi uses in which they advocate fa precisely on the ground that ordinary people can apply them accurately and directly without needing extensive training or authority.

13 - Graham 1989, p. 275. As I will argue below, the implicit suggestion that Legalists use fa only of the standards of punishment rather than of reward is wrong. One of the most famous and most strictly formulated examples of $f a$ is Shang Yang's scheme of reward and advancement discussed below. The conclusion that fa "contract" for this reason is an artifact of the decision to translate fa as "laws," not an empirical observation of its use in the texts.

14 - Ames 1983, p. 108.

15 - That is, Ames uses the hypothesis that the character meant standards at first and then meant law mainly to entitle him to identify which textual comments by different writers were about penal law. Before Xunzi, he identifies the attitude toward penal law by looking for what philosophers say about xing punishment or zhengadministration. After Xunzi, he identifies these doctrines by looking for what they say about $\mathrm{fa}^{\text {standards. }}$. He might have intended this procedure indirectly to justify the usual translation practice by showing that it can make sense of the development of legal thought. But that would require that he compare the overall coherence of his account with one produced by the hypothesis that fa continued to mean standards. He says nothing about what doctrines would have been expressed on the assumption that fa still had its original sense.

16 - He does, however, assure us that, on the basis of his own examination of the uses in ail the classical texts, he drew the conclusion he 
announces. It is the details of that examination process that would have interested us here. And about that examination he says no more. He doesn't explain what principles guided his examination or how he justified his conclusion.

17 - We may call systems laws in the limiting case where the authoritative determination is by chance or divine intervention-trial by combat, survival, oracle, etc.

18 - There is no one, including God, who makes something morally right by saying "It is right." Moral laws, like scientific laws, are hypotheses tested by reason, subject to rational revision when they lead to unacceptable consequences.

19 - Graham (1989), Bodde (1981), and Needham (1954) address the issue of Natural Law and do find alleged counterparts, but the counterparts are not descriptive, universal statements in anything resembling an axiomatic or law-like explanatory theory. They are simple assertions of natural regularities ( $z e^{i f \ldots t \text { then }}$ used nominally). Nothing in Chinese thought much resembles the Western view of a rationally ordered universe describable by a kind of deductive system of explanatory law-like statements.

20 - I would prefer to say "against penal law." Schwartz and Ames, among others, hold that Confucius actually favors punishment and that these are merely arguments about the lesser importance of laws relative to $/ i^{\text {ritual }}$.

21 - For example, (a) it would not as freely invite a theory collapsing penal law into a natural pattern of regularities (descriptive laws); (b) arguments about the application of law to different strata of society will be treated as policy arguments rather than arguments about the essential form of law; (c) since it would resist individuation, they would be less likely to treat punishment as linked retributively to particular laws; etc.

22 - As I noted above, some hold out against the dominant view that Confucius opposes punishment. I discuss these arguments in greater detail in Hansen 1992. I will not address them here.

23 - "The Facts Concerning the Recent Resignation" [1867].

24 - See Schwartz 1985, p. 327.

25 - Translation adapted from Bodde and Morris, in Bodde 1981, p. 178. Ames disputes Bodde and Morris' contention that this passage reflects Confucius' attitude and that this line is consistent with a similar passage which cites Confucius as criticizing making a code public. That passage focuses more emphatically on diminishing the

Chad Hansen 
authority of the scholars. That less-detailed charge is clearly consistent with the elaboration I give above. It is especially so when combined with Confucius' frequent criticism of litigation, glibness, and contentiousness and the rectification-of-names theory discussed below.

26 - Analects 13:3.

27 - This is a different fa from the one at issue.

28 - Confucius says that if government does not rectify names, then language will not flow smoothly, social affairs will not come into effect, liritual and yue ${ }^{\text {music }}$ will not flourish, punishments will miss the mark, and therefore people will not know how to govern hand and foot.

29 - This suggests, in favor of Ames' view, that Confucius cannot legitimately have rejected punishment on this ground while still accepting li. He must face the interpretative problem in either case. See below for other possible differences that would account for Confucius' accepting li while rejecting xing promulgatedpunishment codes.

30 - See Hsiao 1979, p. 368.

31 - The central texts, here, are the opening sections of all three versions of the Fei Ming chapter. For more detailed interpretative arguments for these conclusions, see the discussion in Hansen 1985 and 1982.

32 - For the detailed argument again, see Hansen 1985 and 1982.

33 - Graham identifies biaognomen as a system of aligning posts used to mark, record, or calculate the position of the sun. See Graham 1978, pp. 369-371. This reinforces the impression given by a remark found in the other two versions that trying to fix $y a n^{\text {language }}$ without $f a$ is like trying to fix the point of sunrise and sunset on a potter's wheel.

34 - Rickett 1985, p. 128.

35 - See Graham's discussion in Graham 1978, pp. 343-349.

36 - The connection of Daoism and Legalism is a complicated matter. The appeal here to Shendao and this Daoist point is only part of the story. For more, see Hansen 1992, pp. 204-209, 401 n. 12.

37 - This assumption that skepticism results in disorder is clearly a view he learned from his authoritarian Confucian mentor, Xunzi. Daoists are fond of suggesting (not proving) that relativism and skepticism would lead to tolerance and peace, not disorder and war. Another Daoist response, Zhuangzi's, is to wonder if disorder is so much worse than order anyway. It clearly depends on which order is the alternative. 
38 - W. K. Liao, Han Fei-Tzu: Works from the Chinese, vol. 2, pp. 11-18, "Inner Congeries of Sayings, Lower Series: Six Minutiae" (bk. 10).

39 - Han Feizi, chap. 50, "Revealing Learning."

40 - This point follows Tang (1975, p. 507), who notes both a Zhuangzi and Xunzi antecedent for this attitude in Han Feizi.

41 - This is the general point of the Liu-fan ${ }^{\text {Six Reversals }}$ chapter.

42 - Han Feizi, chap. 49, "Five Vermin" (SBBY ed., 19:6B).

43 - Ibid., 1:3:9A. This statement of frustration echoes Xunzi, of course, and reinforces the suspicion that neither of them understood the analytic tradition.

44 - Ibid., chap. 50, "Revealing Learning," (SBBY ed., 19:9B).

45 - Ibid., 19: 10B.

46 - Even here we should note, as we should in Zhuangzi's case, that this is not an argument about psychological egoism or individualism. Han Feizi describes distortion by positional role perspective, not from pure ego or self-interest. We calculate from our position, not necessarily from the fixed perspective of our rational, individualist ego. Tradition emphasizes the implicit rejection of Confucianism's family-to-politics analogy. I think it is only a minor aspect of the argument here.

47 - Rickett 1985, p. 236.

48 - See Tang 1975, vol. 1, p. 509.

49 - Ibid., p. 511.

50 - Rickett 1985, p. 241.

51 - Han Feizi, chap. 6, "Having Criteria" (SBBY ed., 2:1B-2A).

52 - One imagines a law being passed against deceiving the king. But if that is all that is involved in the technique, then this point would not figure in any central way in the justification of fa in general. The alleged benefit here is not a result of the system of relying on fa but the existence of a specific content in the rules. It is no more relevant to the system of laws than is any other random action that the laws might target for punishment. Further, the proposed rule will not technically prevent deceit - it will merely discourage it by punishing it if it is discovered. If deceit is successful, laws are useless against it. Whereas, if we think of $f a$ as standards governing language use, the relationship claimed here is much more direct and relevant to preventing deceit itself.

53 - Han Feizi, chap. 6, "Having Criteria" (SBBY ed., 2:3B).

Chad Hansen 
54 - Chan 1963, p. 259.

55 - Remember, I treat the explanation that says "you pass a law against $i t^{\prime \prime}$ as an unsatisfying explanation because that relies on some specific content of laws rather than the rule of law as an institutional structure.

56 - Tang 1975, vol. 1, p. 515.

57 - Commentators complain that the boundary between shumethods and $\mathrm{fa}^{\text {standards }}$ is not clear in the Han Feizi. This doctrine is particularly troubling because, on the standard interpretation, the relation of command and punishment should belong to the realm of fa. But Han Feizi seems to include it among shumethods of controlling ministers. It counts in favor of the present interpretation that we can take Han Feizi's classification of the technique of xing-ming punishment-name at face value and still understand why fa would be a necessary accompanying strategy. We need clear standards for the application of names before we can use the technique of punishing people for transgressing the boundaries of their names.

58 - Hsiao 1979, p. 400.

59 - Han Feizi, chap. 13, "Mr. Ho" (SBBY ed., 4:11B).

60 - Hsiao 1979, p. 399. Shang Yang is surprisingly more emphatic about taking the people's point of view in giving this argument than is Han Feizi. Han Feizi barely hints at this point and usually buries it in his broader argument that limiting the officials' arbitrary discretion prevents their getting control of the two handles of power-punishment and reward.

61 - Ibid. Notice that the text makes it clear that the fa are neither the ling ${ }^{\text {orders }}$ nor the ming $^{\text {mandates }}$, but the people have to know both for guidance in the State. The orders would be closer to the laws in our sense and the fa are the standards for interpreting them.

62 - Schwartz 1985, pp. 331-332.

63 - Dingfa; see chap. 43 (17:6b:9-11).

64 - Tang 1975, vol. 1, p. 518.

65 - Chosen from Watson's translation of the things fa allegedly can accomplish (Watson 1964, pp. 14-16).

\section{WORKS CITED}

Ames, Roger. 1983. The Art of Rulership: A Study in Ancient Chinese Political Thought. Honolulu: University of Hawaii Press. 
Blackburn, Simon. 1984. Spreading the Word: Groundings in the Philosophy of Language. Oxford: Clarendon Press.

Bodde, Dirk. 1981. Essays on Chinese Civilization. Princeton: Princeton University Press.

Chan, Wing-tsit. 1963. A Source Book in Chinese Philosophy. Princeton: Princeton University Press.

Creel, Herrlee G. 1970. The Origins of Statecraft in China. Chicago: University of Chicago Press.

- 1974. Shen Pu-hai. Chicago: University of Chicago Press.

Davidson, Donald. 1984. Inquiries into Truth and Interpretation. Oxford: Oxford University Press.

Gibbard, Allan. 1990. Wise Choices, Apt Feelings: A Theory of Normative Judgment. New York: Oxford University Press.

Graham, Angus. 1978. Later Mohist Logic, Ethics and Science. Hong Kong and London: Chinese University Press.

- 1989. Disputers of the Tao: Philosophical Argument in Ancient China. La Salle, Illinois: Open Court.

Grandy, Richard. 1973. "Reference Meaning and Belief." The Journal of Philosophy 70:439-452.

Han, Feizi. 1968. Han Feizi. SBBY edition. Taiwan: Zhonghua Shuju.

Hansen, Chad. 1985. "Chinese Language, Chinese Philosophy, and 'Truth'." Journal of Asian Studies 44 (3).

- 1992. A Daoist Theory of Chinese Thought. New York: Oxford University Press.

Hsiao, Kung-chuan. 1979. A History of Chinese Political Thought. Volume 1: From the Beginnings to the Sixth Century A.D. Trans. F. W. Mote. Princeton: Princeton University Press.

Liao, W. K. 1938, 1959. Han Fei-Tzu: Works from the Chinese. Vol. 1 and 2. London: Arthur Probstl.

Needham, Joseph. 1954. Science and Civilisation in China. Vol. 2. Cambridge: Cambridge University Press.

Quine, W. V. O. 1960. Word and Object. Cambridge, Massachusetts: MIT Press.

Pfister, Lauren. 1991. "Some New Dimensions in the Study of the Works of James Legge (1815-1837): Part 1." Sino-Western Cultural Relation Journal 12.

Rickett, Allyn W. 1985. Guanzi: Political, Economic, and Philosophical Essays from Early China. Princeton: Princeton University Press.

Chad Hansen 
Schwartz, Benjamin. 1985. The World of Thought in Ancient China. Cambridge, Massachusetts: Harvard University Press.

Stitch, Stephen. 1983. From Folk Psychology to Cognitive Science: The Case against Belief. Cambridge, Massachusetts: MIT Press.

Tang, Jun-i. 1975. Zhongguo zhexue yuanlun: Yuan dao pian. Vols. 1-3. Hong Kong: Ronsheng chubanshe.

Watson, Burton. 1964. Han Fei-tzu: Basic Writings. New York: Columbia University Press.

Wu, Yi. 1986. Chinese Philosophical Terms. Lanham, Maryland: University Press of America. 